\title{
Comparison of Brief Health Literacy Screens in the Emergency Department
}

\author{
By
}

Eric Kiechle

\begin{abstract}
A Master's Paper submitted to the faculty of the University of North Carolina at Chapel Hill in partial fulfillment of the requirements for the degree of Master of Public Health in the Public Health Leadership Program
\end{abstract}

Chapel Hill

2013

Advisor:

Date

Second Reader: 


\section{Table of Contents}

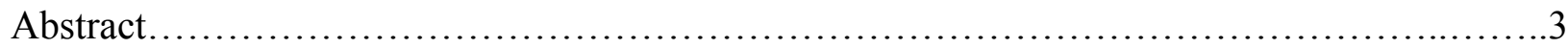

Systematic Review

Manuscript................................................................4

References...............................................................

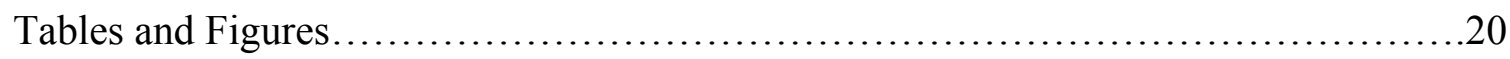

Research Study

Manuscript............................................................. 28

References............................................................43

Tables and Figures.................................................... 45

Acknowledgements...........................................................5 


\begin{abstract}
Lower levels of health literacy, the skills needed to appropriately navigate a health care system, are associated with a number of negative health outcomes, from higher rates of Emergency Department visits to decreased vaccination rates. Measuring health literacy is of great interest both clinically and in research to further describe these relationships and to find ways of mitigating these outcomes, but there are many tools available. Their varying characteristics may affect the way we understand these relationships. This paper includes a systematic review and an original research component. In the review, we compare self-reported measures of health literacy to performance-based measures, with an eye towards their differential abilities to predict health outcomes. The evidence from the three included studies suggests that these measures differ in unpredictable ways in their capacities to detect health outcomes, and that instrument choice may determine the presence or magnitude of these associations. In the research study, we compare five brief measures of health literacy (Newest Vital Sign, SILS, brief screening questions, REALM-R and METER) to a longer referent standard (S-TOFHLA) in 400 Southeastern suburban Emergency Department patients. Our findings indicate that the Newest Vital Sign is best able to replicate the S-TOFHLA, but that all tools could be considered for health literacy screening in the ED. We find that cutoffs can be modified to select for test characteristics and the proportion of patients deemed health literate, and suggest that future health literacy screening studies provide a rationale for the measurement tool and cutoff used, based on the skill set targeted and intent behind screening, or even consider using multiple tools. Future research will need to go beyond the validation of these tools in the ED, and shed more light on their associations with health outcomes.
\end{abstract}




\section{Use of Performance-Based and Self-Reported Measures of Health Literacy and Numeracy in Predicting Health Outcomes: a Systematic Review}

\section{INTRODUCTION}

Health literacy is a broader construct than traditional literacy, and has been defined as a “constellation of skills, including the ability to perform basic reading and numerical tasks required to function in the health care environment". ${ }^{1}$ The U.S. Department of Education's last national assessment of adult literacy in 2003 measured this concept separately from traditional literacy, and found that $36 \%$ of Americans have below intermediate health literacy. ${ }^{2}$. Lower levels of health literacy are associated with a number of negative health outcomes, including higher mortality, increased use of emergency departments and inpatient facilities, and lower use of preventive services. ${ }^{3}$

No gold standard currently exists for measuring health literacy, but the tools most often used to measure health literacy in clinical studies are the Short Test of Functional Health Literacy in Adults (S-TOFHLA) and the Rapid Estimate of Adult Literacy in Medicine (REALM). ${ }^{4,5}$ Both tests are performance-based, or objective in their assessment of health literacy. ${ }^{6}$ The former test requires patients to select one of four words to fit into 36 blanks scattered through two medical passages, while the latter assesses pronunciation of 66 medical words of varying difficulty. For the numeracy component of health literacy, the most common tools used are the objective questions developed by Schwartz and Woloshin and the questions later developed by Lipkus. ${ }^{7,8}$

Self-reported, or subjective tools that ask patients to self-rate their literacy, ${ }^{9,10}$ and numeracy ${ }^{11}$ have been validated against these older tools. People with low health literacy may have feelings of embarrassment when they must perform or display their skills publically. ${ }^{12}$ Self- 
reported questions are potentially shorter and less embarrassing to administer ${ }^{13}$, which could allow for more efficient research into health literacy, as well as fewer negative feelings for patients involved in this type of research.

No reviews to date have focused on the differences between self-reported subjective measures of health literacy and performance-based objective measures of health literacy and their relationship to health outcomes. This review assessed studies that specifically used both types of measures and also reported outcomes in trying to determine if there are differences in their predictive ability.

\section{METHODS}

\section{INCLUSION/EXCLUSION CRITERIA}

A full list of inclusion/exclusion criteria is included in Table 1, but was modeled on the 2011 systematic review by AHRQ. ${ }^{3}$ Inclusion criteria included English-language studies that focused on patients and caregivers of all ethnicities. Studies had to measure health literacy and/or numeracy using both objective and subjective tools. Any health outcomes (disease-specific outcomes, general health status) as well as use of health services were considered, although health knowledge and patient-provider relationships were not. Both cross-sectional and prospective study designs were allowed.

\section{SEARCH STRATEGY}

PubMed was queried using the same search string as the latest Agency for Healthcare Research and Quality funded systematic review of low health literacy and health outcomes ${ }^{3}$ (full 26 string search included in Table 2). The start date was chosen to be one month prior to the search used in that review (January $1^{\text {st }} 2011$ ). Since no specific MeSH terms target health literacy 
articles, a variety of terms were included (literacy, numeracy, names of specific tools). English language studies only were searched. All study design types were allowed, but case reports, editorials and letters were excluded from the search. Additionally, the included study tables from the past review were examined to identify studies prior to the search date met inclusion/exclusion criteria. The included studies were assessed for sources of selection bias, confounding, and measurement bias but were too heterogeneous to use a single quality assessment scale.

\section{RESULTS}

One author (EK) reviewed the 878 titles from the initial PubMed search. Titles that appeared relevant were identified and abstracts were procured for 176 of those articles (Figure). The latter were reviewed, and if no exclusion criteria were identified, the article measured health literacy and focused on any health outcome, the full text was retrieved. In this way, 69 full text articles were reviewed for inclusion. Of these, 67 were excluded because they did not meet inclusion criteria. Specifically, 55 did not assess health literacy and/or numeracy subjectively, 5 did not assess health literacy/numeracy objectively, 6 did not measure any applicable outcome, and 1 measured both subjective and objective health literacy, but did not stratify its outcome of self-reported health outcome by tool used for measurement (Table 3). Two articles met inclusion criteria and are assessed in this review. Additionally, one article was identified by reviewing the abstracts from all "fair" and "good" rated studies from the 2011 Berkman review, which also included those articles carried forward from the original AHRQ review. The characteristics of the full-text articles reviewed are included in Table 3.

The three articles included in the final review varied in their focus and measurements. The Haun ${ }^{14}$ and Hirsh ${ }^{15}$ articles both included health literacy measurements as part of their protocols, while the Ciampa ${ }^{6}$ article focused on numeracy. The objective and subjective 
measurements used, the health outcomes considered, the study designs and settings are summarized in Table 4. None of the studies focused specifically on the differences between measurement types for predicting health outcomes, but all three reported health outcomes by measurement type, allowing conclusions to be drawn.

The performance of the various tests for detecting adequate health literacy or numeracy varied based on study setting. In Measurement Variation Across Health Literacy Assessments: Implications for Assessment Selection in Research and Practice ${ }^{14}$, Haun et al. examined the differences between three health literacy instruments and associated factors in eight ambulatory VA clinics in the Southeastern United States, collecting information from a convenience sample of 378 English speaking veterans. They used the aforementioned S-TOFHLA and REALM tests, as well as the BRIEF, a combination of four self-reported health literacy questions, including three questions shown in the literature to predict inadequate/marginal health ${ }^{16}$ and a fourth item geared at measuring oral health literacy ("How often do you have a problem understanding what is told to you about your medical condition?"). ${ }^{17}$ The outcomes considered were collected crosssectionally, and consisted of three dichotomous indicators (diabetes, high blood pressure, and past stroke). This study found that $83 \%$ of its sample had adequate health literacy on the STOHFLA (a score of $>23$ ), compared to $63 \%$ with the REALM (using a score of $61-66$ ) and $43 \%$ with the BRIEF (using a score of 17-20 based on the summed likert scores on the four questions).

In Limited Health Literacy is a Common Finding in a Public Health Hospital's Rheumatology Clinic and is Predictive of Disease Severity ${ }^{15}$, Hirsch et al. interviewed 110 adult rheumatology clinic patients to determine if health literacy, measured by S-TOFHLA, REALM and their subjective measure, a single validated question regarding confidence filling out medical 
forms (referred to in the article as SILS) were linked to disease severity, as assessed through a physician completed tool (the 28 item Disease Activity Scale, or DAS-28) and a patient completed tool (the Multidimensional Health Assessment Questionnaire, or MDHAQ) . They found that $65 \%$ of their sample had adequate health literacy on the S-TOFHLA, compared to $51 \%$ on the REALM and $70 \%$ on the SILS.

In Patient Numeracy, Perceptions of Provider Communication, and Colorectal Cancer Screening Utilization, ${ }^{6}$ Ciampa et al. used data from the 2007 National Cancer Institute Health Information Trends Survey (HINTS) to connect numeracy, measured by one self-reported question (how hard or easy the respondents found it to interpret medical statistics) and one objective question (asking respondents to pick the largest risk from three ratios) with perceptions of provider communication and up-to-date colorectal cancer screening status. Data were collected by mail $(\mathrm{n}=1808)$ and by phone $(\mathrm{n}=2325)$. Using the objective question, $77.4 \%$ had adequate numeracy, compared to $60.6 \%$ using the subjective question (using a dichotomous measure of very easy/easy or very hard/hard to interpret medical statistics).

Two of the studies, the Haun and Ciampa articles, examined agreement regarding health literacy or numeracy status between measurement tools. In the Haun study, the Pearson correlation between the S-TOFHLA and the REALM was 0.61 ( $p<0.01)$, between the STOFHLA and the BRIEF was $0.42(\mathrm{p}<0.01)$ and between the REALM and the BRIEF was 0.40 $(\mathrm{p}<0.01)$. In the Ciampa article, the Kendall Tau-b correlation coefficient between subjective and objective numeracy was $0.09(\mathrm{p}<0.01)$, and the article states that "[they] behaved as separate constructs $[\ldots]$, the weak correlation between subjective and objective numeracy in this sample suggests that individuals may have a distorted understanding of their own ability to understand and use numbers". 
The results for prediction of outcomes were heterogeneous. In the two studies looking at health literacy, the subjective measure was associated with health outcomes more reliably than the objective measure. In the rheumatologic study, only the SILS was found to be significantly associated with MDHAQ score (beta coefficient of an improvement of 1 on the 4 point likert scale $=-0.33696, p=0.008)$ while only trends were found for the S-TOFHLA and the REALM. This pattern persisted after adjustment, with higher subjective health literacy still being significantly associated with lower functional disability as measured by the MDHAQ. None of the health literacy measures were significantly associated with the DAS-28 disease severity measure, although the SILS came closest with a coefficient of $-0.47178(\mathrm{p}=0.14)$ (i.e. for each incrementally more confident response on the SILS, the disease activity score would be about half a point lower). In the Haun article, only the BRIEF test came close to being significantly associated with diabetic status $(\mathrm{p}=0.115)$, unlike the REALM $(\mathrm{p}=0.358)$ and S-TOFHLA $(p=0.368)$. Both the S-TOFHLA $(p=0.036)$ and the BRIEF $(p=0.008)$ were significantly associated with high blood pressure. Only the S-TOFHLA was associated with history of stroke $(p=0.037)$, while there was a trend for the BRIEF (0.111). The REALM was therefore not significantly associated with any of the outcomes in either of the health literacy studies, while the SILS performed better than the S-TOFHLA in the rheumatology study and the S-TOFHLA was associated with two of three health outcomes compared to just one for the BRIEF in the Haun study.

In the numeracy study, no p-value was reported for the small differences found between subjective and objective numeracy and up-to-date colorectal cancer screening status. Among respondents with high objective numeracy, $58.5 \%$ were up-to-date, compared to $45.7 \%$ among 
those with low objective numeracy. Among respondents with high subjective literacy, 53.4\% were up-to-date on screening, compared with $47.8 \%$ among those with low subjective numeracy.

\section{DISCUSSION}

This systematic review highlights important information about the differences between subjective and objective health literacy and numeracy measurements, and the implications for predicting outcomes. Our review finds that there are insufficient data to support using an objective over a subjective tool, and that these tools differ in their measurements as well as their associations with health outcomes.

All three articles showed that tool selection greatly affects the proportion of patients that will be deemed to possess adequate health literacy, with objective tests categorizing more patients as having adequate health literacy or numeracy than subjective tools in two studies (Haun and Ciampa) and the reverse being true in the Hirsh article. These differences draw attention to the thresholds used for subjective measures. While the thresholds for objective measures are often defined in the validating studies for those tools and carried forward without change ${ }^{4,5}$ subjective measures are more malleable introducing measurement bias into studies that use them and vary thresholds. Some studies consider questions individually, such as the confidence question in the Hirsh article, while others pool them into composite measures, like the BRIEF in the Haun article which includes four questions. Past studies have used composites with just three questions ${ }^{18}$ or singled out different individual questions as a "single item literacy screener". ${ }^{10}$ Likewise, reducing a question to a dichotomous indicator rather than using all of the possible responses reduces the accuracy of the tool. The lack of consensus on how to measure subjective literacy and numeracy leads to diverging estimates of the prevalence of adequate health literacy. Hence it is not surprising that in the Hirsh article, where a single question was 
used and a score of 4 or 5 out of five was deemed adequate, that $70 \%$ of patients had adequate health literacy, while in the Haun article where anything less than 17 out 20 on four pooled questions was deemed less than adequate, just $43 \%$ were listed as having adequate health literacy. The sensitivity of these subjective measures for detecting limited health literacy can be increased by pooling more questions, or lowering thresholds, with a resulting loss in specificity.

Two of the articles highlighted the lack of agreement between subjective and objective measures of health literacy and numeracy, with low correlation coefficients underlining the different constructs being measured and the difference in skills measured by each instrument. The 2009 systematic review of health literacy and outcomes by the AHRQ ${ }^{3}$ draws attention to the lack of a gold-standard instrument, and other studies have drawn attention to the lack of correlation stemming from different constructs being measured between self-report items and task-based items. ${ }^{19,20}$ Since this research is ongoing, some authors suggest using more than one literacy-screening tool or selecting an instrument based on the population and skill set being $\operatorname{assessed~}^{17,20}$ to gather as much information as possible as definitions of health literacy and conceptual frameworks catch up to the instruments.

In terms of instrument capacity to predict poor outcomes, the results of this review are mixed. In the two health literacy studies assessed, the subjective tool consistently outperformed the REALM test, while comparison with the S-TOFHLA found heterogeneous results; one study found the SILS to be better at predicting lower patient scores on the MDHAQ, while the other found that the BRIEF and S-TOFHLA were alternatingly more strongly associated with health outcomes, depending on the specific outcome of interest. In the numeracy article reviewed, there were small differences in the proportion of respondents up-to-date on their screening, but the authors did not assess the significance of these differences. One can conclude from these 
heterogeneous results that a downstream consequence of the different constructs measured by subjective and objective tools are different predictive abilities that may depend on the outcome considered. It is not possible to say based on the studies considered whether subjective or objective tools are more predictive of outcomes, but it is clear that certain outcomes are associated exclusively with a specific tool, as evidenced by all three of our studies, and that subjective tools being weakly correlated with objective tools, the use of self-reported instruments could predict a different set of outcomes that would be missed by objective instruments, and vice-versa.

There are many limitations to the literature reviewed here. For one, all study designs considered were cross-sectional, making it impossible to discuss the role of causality in the associations found between health literacy and outcomes. Randomized controlled trials, or other prospective study designs, could more accurately describe the relationship between the two. No other reviews have compared the use of subjective and objective screening measures, so our work cannot be evaluated against the literature, and no specific studies have tried to study the differences in subjective and objective measurements' effects on outcomes; all three of our studies discussed this relationship incidentally and were focused on other key questions.

Cross-sectional study designs introduce a large potential for selection bias and confounding. In multivariate analyses, the Hirsh study controlled for age, race, gender, marital status, education, tobacco, and disease specific markers/treatment, making a stronger case for the significance of the relationship between SILS and the MDHAQ scores. In contrast, the associations between health outcomes and screening instrument were from bivariate analyses in the Haun article, introducing the possibility of confounders mediating these relationships. In the Ciampa article, no tests of association were performed to measure the significance of the 
difference between the subjective and objective tests.

The sampling strategy used varied by article. The Haun article used a convenience sample of mostly older adults at various VA ambulatory clinics, and did not report the total number of patients approached to reach their target. Similarly, the Hirsh article does not discuss how many patients were approached, nor if the 110 patients were recruited systematically or through a convenience sample. Both these studies may suffer from a selection bias in which only patients with higher health literacy might enroll, while those with lower health literacy may have declined for fear of embarrassment or shame, a concern reported by other studies. ${ }^{12,21}$ This could have weakened the association found between health literacy and health outcomes. In the Ciampa article, this is likely less concerning since the information was collected by mail or by phone, and the tools used were succinct and a minor focus of the survey as a whole. This would likely mitigate the selection bias associated with embarrassment or shame. Additionally, using random digit dialing and a USPS list for addresses would create a largely nationally representative sample, although possibly biasing the result towards older and wealthier adults who have a landline, and a home address.

Beyond the limitations of the literature, there may have been limitations to our search strategy; using the same search string focused on outcomes research that the AHRQ review employed, we may have missed instrument validation studies that cross-sectionally evaluated some outcomes. However, the wide scope of the search strategy makes this unlikely. Similarly, such studies would be unlikely to have been included in the appendices of the past reviews which were also searched. 


\section{CONCLUSION}

This review found that there is a paucity of data that precludes any conclusions about the advantages of subjective or objective instruments of health literacy/numeracy on predicting health outcomes. The evidence reviewed showed that there is a lack of agreement between these two types of instruments, and that their association with health and other outcomes is varied, with subjective tools being more strongly associated with outcomes in one study, and mixed results being found in the others.

The implication for current practice is significant; current research papers that connect health literacy or numeracy with outcomes may miss the presence or the magnitude of an effect solely because of the specific instrument selected. Until further research improves our understanding of the underlying construct we are trying to measure, clinicians and researchers need to decide what skill they are trying to measure, and either carefully deliberate on which instrument to use, or if time allows, possibly use multiple instruments, including both objective and subjective tools. Subjective instruments have the advantage of being generally faster to administer and less embarrassing for patients ${ }^{17}$ but may not be measuring the same construct as objective tools, which correlated more often with each other in our review.

Future research is needed to outline the specific skills measured by the multitude of health literacy and numeracy instruments available. Prospective studies that use multiple instruments, including subjective ones, will shed more light on their differential abilities to predict health and other outcomes. 


\section{REFERENCES}

1. Parker RM, Williams MV, Weiss BD, Baker DW, Davis TC, Doak CC, et al. Health literacy-report of the council on scientific affairs. JAMA. 1999;281(6):552-7.

2. Kutner M, Greenburg E, Jin Y, Paulsen C. The health literacy of america's adults: Results from the 2003 national assessment of adult literacy. NCES 2006-483. National Center for Education Statistics. 2006.

3. Berkman ND, Sheridan SL, Donahue KE, Halpern DJ, Crotty K. Low health literacy and health outcomes: An updated systematic review. Ann Intern Med. 2011;155(2):97.

4. Baker DW, Williams MV, Parker RM, Gazmararian JA, Nurss J. Development of a brief test to measure functional health literacy. Patient Educ Couns. 1999.

5. Davis TC, Long SW, Jackson RH, Mayeaux E, George RB, Murphy PW, et al. Rapid estimate of adult literacy in medicine: A shortened screening instrument. Fam Med. 1993;25(6):391.

6. Ciampa PJ, Osborn CY, Peterson NB, Rothman RL. Patient numeracy, perceptions of provider communication, and colorectal cancer screening utilization. J Health Commun. 2010;15(S3):157-68.

7. Woloshin S, Schwartz LM, Byram S, Fischhoff B, Welch HG. A new scale for assessing perceptions of chance A validation study. Medical Decision Making. 2000;20(3):298-307.

8. Lipkus IM, Samsa G, Rimer BK. General performance on a numeracy scale among highly educated samples. Medical Decision Making. 2001;21(1):37-44.

9. Chew LD, Griffin JM, Partin MR, Noorbaloochi S, Grill JP, Snyder A, et al. Validation of screening questions for limited health literacy in a large VA outpatient population. Journal of General Internal Medicine. 2008;23(5):561-6.

10. Morris NS, MacLean CD, Chew LD, Littenberg B. The single item literacy screener: Evaluation of a brief instrument to identify limited reading ability. BMC Family Practice. 2006;7(1):21.

11. Fagerlin A, Zikmund-Fisher BJ, Ubel PA, Jankovic A, Derry HA, Smith DM. Measuring numeracy without a math test: Development of the subjective numeracy scale. Medical Decision Making. 2007;27(5):672-80.

12. Wolf MS, Williams MV, Parker RM, Parikh NS, Nowlan AW, Baker DW. Patients' shame and attitudes toward discussing the results of literacy screening. J Health Commun. 2007;12(8):721-32.

13. Chew LD, Bradley KA, Boyko EJ. Brief questions to identify patients with inadequate health literacy. health. 2004;11:12.

14. Haun J, Luther S, Dodd V, Donaldson P. Measurement variation across health literacy assessments: Implications for assessment selection in research and practice. J Health Commun. 2012;17 Suppl 3:14159.

15. Hirsh JM, Boyle DJ, Collier DH, Oxenfeld AJ, Nash A, Quinzanos I, et al. Limited health literacy is a common finding in a public health hospital's rheumatology clinic and is predictive of disease severity. $\mathrm{J}$ Clin Rheumatol. 2011 Aug;17(5):236-41.

16. Chew LD, Griffin JM, Partin MR, Noorbaloochi S, Grill JP, Snyder A, et al. Validation of screening questions for limited health literacy in a large VA outpatient population. Journal of General Internal Medicine. 2008;23(5):561-6.

17. Haun J, Dodd V, Varnes J, Graham-Pole J, Rienzo B, Donaldson P. Testing the brief health literacy screening tool: Implications for utilization of a BRIEF health literacy indicator. Fed Pract.

2009;26(12):24-8.

18. McNaughton C, Wallston KA, Rothman RL, Marcovitz DE, Storrow AB. Short, subjective measures of numeracy and general health literacy in an adult emergency department. Acad Emerg Med. 2011

Nov;18(11):1148-55.

19. Begoray DL, Kwan B. A canadian exploratory study to define a measure of health literacy. Health Promot Internation. 2012;27(1):23-32. 
20. Saldana S. Performance of health literacy tests among older adults with diabetes. Journal of general internal medicine. 2012;27(5):534-40.

21. Parikh NS, Parker RM, Nurss JR, Baker DW, Williams MV. Shame and health literacy: The unspoken connection. Patient Educ Couns. 1996;27(1):33-9.

22. Altsitsiadis E, Undheim T, de Vries E, Hinrichs B, Stockfleth E, Trakatelli M, et al. Health literacy, sunscreen and sunbed use: An uneasy association. Br J Dermatol. 2012 Aug;167 Suppl 2:14-21.

23. Mitchell SE, Sadikova E, Jack BW, Paasche-Orlow MK. Health literacy and 30-day postdischarge hospital utilization. J Health Commun. 2012;17 Suppl 3:325-38.

24. Boxell EM, Smith SG, Morris M, Kummer S, Rowlands G, Waller J, et al. Increasing awareness of gynecological cancer symptoms and reducing barriers to medical help seeking: Does health literacy play a role? J Health Commun. 2012;17 Suppl 3:265-79.

25. Arnold CL, Rademaker A, Bailey SC, Esparza JM, Reynolds C, Liu D, et al. Literacy barriers to colorectal cancer screening in community clinics. J Health Commun. 2012;17 Suppl 3:252-64.

26. Mosher HJ, Lund BC, Kripalani S, Kaboli PJ. Association of health literacy with medication knowledge, adherence, and adverse drug events among elderly veterans. J Health Commun. 2012;17 Suppl 3:241-51.

27. Shaw SJ, Armin J, Torres CH, Orzech KM, Vivian J. Chronic disease self-management and health literacy in four ethnic groups. J Health Commun. 2012;17 Suppl 3:67-81.

28. Rademakers J, Nijman J, van der Hoek L, Heijmans M, Rijken M. Measuring patient activation in the netherlands: Translation and validation of the american short form patient activation measure (PAM13). BMC Public Health. 2012 Jul 31;12:577,2458-12-577.

29. Penaranda E, Diaz M, Noriega O, Shokar N. Evaluation of health literacy among spanish-speaking primary care patients along the US--mexico border. South Med J. 2012 Jul;105(7):334-8.

30. Noureldin M, Plake KS, Morrow DG, Tu W, Wu J, Murray MD. Effect of health literacy on drug adherence in patients with heart failure. Pharmacotherapy. 2012 Sep;32(9):819-26.

31. Garrett GM, Citi AM, Gansky SA. Parental functional health literacy relates to skip pattern questionnaire error and to child oral health. J Calif Dent Assoc. 2012 May;40(5):423-30.

32. Coffman MJ, Norton CK, Beene L. Diabetes symptoms, health literacy, and health care use in adult latinos with diabetes risk factors. J Cult Divers. 2012 Spring;19(1):4-9.

33. Hudon C, Fortin M, Poitras ME, Almirall J. The relationship between literacy and multimorbidity in a primary care setting. BMC Fam Pract. 2012 Jul 3;13:33,2296-13-33.

34. Bostock S, Steptoe A. Association between low functional health literacy and mortality in older adults: Longitudinal cohort study. BMJ. 2012 Mar 15;344:e1602.

35. McCarthy DM, Waite KR, Curtis LM, Engel KG, Baker DW, Wolf MS. What did the doctor say? health literacy and recall of medical instructions. Med Care. 2012 Apr;50(4):277-82.

36. Huang JS, Tobin A, Tompane T. Clinicians poorly assess health literacy-related readiness for transition to adult care in adolescents with inflammatory bowel disease. Clin Gastroenterol Hepatol. 2012 Jun;10(6):626-32.

37. Curtis LM, Wolf MS, Weiss KB, Grammer LC. The impact of health literacy and socioeconomic status on asthma disparities. J Asthma. 2012 Mar;49(2):178-83.

38. Vassy JL, O'Brien KE, Waxler JL, Park ER, Delahanty LM, Florez JC, et al. Impact of literacy and numeracy on motivation for behavior change after diabetes genetic risk testing. Med Decis Making. 2012 Jul-Aug;32(4):606-15.

39. Bains SS, Egede LE. Association of health literacy with complementary and alternative medicine use: A cross-sectional study in adult primary care patients. BMC Complement Altern Med. 2011 Dec 30;11:138,6882-11-138.

40. Rosman SL, Dorfman D, Suglia SF, Humphrey C, Silverstein M. Predictors of prescription filling after visits to the pediatric emergency department. Pediatr Emerg Care. 2012 Jan;28(1):22-5.

41. McDougall GJ,Jr, Mackert M, Becker H. Memory performance, health literacy, and instrumental activities of daily living of community residing older adults. Nurs Res. 2012 Jan-Feb;61(1):70-5. 
42. Backes AC, Kuo GM. The association between functional health literacy and patient-reported recall of medications at outpatient pharmacies. Res Social Adm Pharm. 2012 Jul-Aug;8(4):349-54.

43. Cappelletti M, Butterworth B, Kopelman M. Numeracy skills in patients with degenerative disorders and focal brain lesions: A neuropsychological investigation. Neuropsychology. 2012 Jan;26(1):1-19.

44. Smith SA, Moore EJ. Health literacy and depression in the context of home visitation. Matern Child Health J. 2012 Oct;16(7):1500-8.

45. Kirk JK, Grzywacz JG, Arcury TA, Ip EH, Nguyen HT, Bell RA, et al. Performance of health literacy tests among older adults with diabetes. J Gen Intern Med. 2012 May;27(5):534-40.

46. Robinson S, Moser D, Pelter MM, Nesbitt T, Paul SM, Dracup K. Assessing health literacy in heart failure patients. J Card Fail. 2011 Nov;17(11):887-92.

47. Lee JY, Divaris K, Baker AD, Rozier RG, Vann WF,Jr. The relationship of oral health literacy and self-efficacy with oral health status and dental neglect. Am J Public Health. 2012 May;102(5):923-9. 48. Jeppesen KM, Hull BP, Raines M, Miser WF. A validation study of the spoken knowledge in low literacy in diabetes scale (SKILLD). J Gen Intern Med. 2012 Feb;27(2):207-12.

49. Martin LT, Haas A, Schonlau M, Derose KP, Rosenfeld L, Rudd R, et al. Which literacy skills are associated with smoking? J Epidemiol Community Health. 2012 Feb;66(2):189-92.

50. Marden S, Thomas PW, Sheppard ZA, Knott J, Lueddeke J, Kerr D. Poor numeracy skills are associated with glycaemic control in type 1 diabetes. Diabet Med. 2012 May;29(5):662-9.

51. Lindquist LA, Go L, Fleisher J, Jain N, Friesema E, Baker DW. Relationship of health literacy to intentional and unintentional non-adherence of hospital discharge medications. J Gen Intern Med. 2012 Feb;27(2):173-8.

52. Hardie NA, Kyanko K, Busch S, Losasso AT, Levin RA. Health literacy and health care spending and utilization in a consumer-driven health plan. J Health Commun. 2011;16 Suppl 3:308-21.

53. Rubin DL, Parmer J, Freimuth V, Kaley T, Okundaye M. Associations between older adults' spoken interactive health literacy and selected health care and health communication outcomes. J Health Commun. 2011;16 Suppl 3:191-204.

54. Telford RD, Cunningham RB, Fitzgerald R, Olive LS, Prosser L, Jiang X, et al. Physical education, obesity, and academic achievement: A 2-year longitudinal investigation of australian elementary school children. Am J Public Health. 2012 Feb;102(2):368-74.

55. Omariba DW, Ng E. Immigration, generation and self-rated health in canada: On the role of health literacy. Can J Public Health. 2011 Jul-Aug;102(4):281-5.

56. Fernandez S, Tobin JN, Cassells A, Diaz-Gloster M, Kalida C, Ogedegbe G. The counseling african americans to control hypertension (CAATCH) trial: Baseline demographic, clinical, psychosocial, and behavioral characteristics. Implement Sci. 2011 Sep 1;6:100,5908-6-100.

57. Morris NS, Grant S, Repp A, Maclean C, Littenberg B. Prevalence of limited health literacy and compensatory strategies used by hospitalized patients. Nurs Res. 2011 Sep-Oct;60(5):361-6.

58. Shibuya A, Inoue R, Ohkubo T, Takeda Y, Teshima T, Imai Y, et al. The relation between health literacy, hypertension knowledge, and blood pressure among middle-aged japanese adults. Blood Press Monit. 2011 Oct;16(5):224-30.

59. Shelton RC, Jandorf L, Ellison J, Villagra C, DuHamel KN. The influence of sociocultural factors on colonoscopy and FOBT screening adherence among low-income hispanics. J Health Care Poor Underserved. 2011 Aug;22(3):925-44.

60. Diug B, Evans S, Lowthian J, Maxwell E, Dooley M, Street A, et al. The unrecognized psychosocial factors contributing to bleeding risk in warfarin therapy. Stroke. 2011 Oct;42(10):2866-71.

61. Lee SY, Tsai TI, Tsai YW, Kuo KN. Health literacy and women's health-related behaviors in taiwan. Health Educ Behav. 2012 Apr;39(2):210-8.

62. Pendlimari R, Holubar SD, Hassinger JP, Cima RR. Assessment of colon cancer literacy in screening colonoscopy patients: A validation study. J Surg Res. 2012 Jun 15;175(2):221-6. 
63. Zoellner J, You W, Connell C, Smith-Ray RL, Allen K, Tucker KL, et al. Health literacy is associated with healthy eating index scores and sugar-sweetened beverage intake: Findings from the rural lower mississippi delta. J Am Diet Assoc. 2011 Jul;111(7):1012-20.

64. McCleary-Jones V. Health literacy and its association with diabetes knowledge, self-efficacy and disease self-management among african americans with diabetes mellitus. ABNF J. 2011 Spring;22(2):25-32.

65. Gardner PH, McMillan B, Raynor DK, Woolf E, Knapp P. The effect of numeracy on the comprehension of information about medicines in users of a patient information website. Patient Educ Couns. 2011 Jun;83(3):398-403.

66. Pagan JA, Brown CJ, Asch DA, Armstrong K, Bastida E, Guerra C. Health literacy and breast cancer screening among mexican american women in south texas. J Cancer Educ. 2012 Mar;27(1):132-7.

67. Miller DP,Jr, Spangler JG, Case LD, Goff DC,Jr, Singh S, Pignone MP. Effectiveness of a web-based colorectal cancer screening patient decision aid: A randomized controlled trial in a mixed-literacy population. Am J Prev Med. 2011 Jun;40(6):608-15.

68. Galesic M, Garcia-Retamero R. Do low-numeracy people avoid shared decision making? Health Psychol. 2011 May;30(3):336-41.

69. Green JA, Mor MK, Shields AM, Sevick MA, Palevsky PM, Fine MJ, et al. Prevalence and demographic and clinical associations of health literacy in patients on maintenance hemodialysis. Clin J Am Soc Nephrol. 2011 Jun;6(6):1354-60.

70. Peterson PN, Shetterly SM, Clarke CL, Bekelman DB, Chan PS, Allen LA, et al. Health literacy and outcomes among patients with heart failure. JAMA. 2011 Apr 27;305(16):1695-701.

71. Patel PJ, Joel S, Rovena G, Pedireddy S, Saad S, Rachmale R, et al. Testing the utility of the newest vital sign (NVS) health literacy assessment tool in older african-american patients. Patient Educ Couns. 2011 Dec;85(3):505-7.

72. Ko Y, Lee JY, Toh MP, Tang WE, Tan AS. Development and validation of a general health literacy test in singapore. Health Promot Int. 2012 Mar;27(1):45-51.

73. Begoray DL, Kwan B. A canadian exploratory study to define a measure of health literacy. Health Promot Int. 2012 Mar;27(1):23-32.

74. Ishikawa H, Yano E. The relationship of patient participation and diabetes outcomes for patients with high vs. low health literacy. Patient Educ Couns. 2011 Sep;84(3):393-7.

75. Macabasco-O'Connell A, DeWalt DA, Broucksou KA, Hawk V, Baker DW, Schillinger D, et al. Relationship between literacy, knowledge, self-care behaviors, and heart failure-related quality of life among patients with heart failure. J Gen Intern Med. 2011 Sep;26(9):979-86.

76. Chaudhry SI, Herrin J, Phillips C, Butler J, Mukerjhee S, Murillo J, et al. Racial disparities in health literacy and access to care among patients with heart failure. J Card Fail. 2011 Feb;17(2):122-7.

77. Bains SS, Egede LE. Associations between health literacy, diabetes knowledge, self-care behaviors, and glycemic control in a low income population with type 2 diabetes. Diabetes Technol Ther. 2011 Mar;13(3):335-41.

78. Chen AM, Yehle KS, Plake KS, Murawski MM, Mason HL. Health literacy and self-care of patients with heart failure. J Cardiovasc Nurs. 2011 Nov-Dec;26(6):446-51.

79. Naik AD, Street RL,Jr, Castillo D, Abraham NS. Health literacy and decision making styles for complex antithrombotic therapy among older multimorbid adults. Patient Educ Couns. 2011

Dec;85(3):499-504.

80. Lindquist LA, Jain N, Tam K, Martin GJ, Baker DW. Inadequate health literacy among paid caregivers of seniors. J Gen Intern Med. 2011 May;26(5):474-9.

81. Dennison CR, McEntee ML, Samuel L, Johnson BJ, Rotman S, Kielty A, et al. Adequate health literacy is associated with higher heart failure knowledge and self-care confidence in hospitalized patients. J Cardiovasc Nurs. 2011 Sep-Oct;26(5):359-67.

82. Sarkar U, Schillinger D, Lopez A, Sudore R. Validation of self-reported health literacy questions among diverse english and spanish-speaking populations. J Gen Intern Med. 2011 Mar;26(3):265-71. 
83. Osborn CY, Paasche-Orlow MK, Bailey SC, Wolf MS. The mechanisms linking health literacy to behavior and health status. Am J Health Behav. 2011 Jan-Feb;35(1):118-28.

84. Martin LT, Schonlau M, Haas A, Derose KP, Rudd R, Loucks EB, et al. Literacy skills and calculated 10-year risk of coronary heart disease. J Gen Intern Med. 2011 Jan;26(1):45-50.

85. Todd L, Harvey E, Hoffman-Goetz L. Predicting breast and colon cancer screening among english-asa-second-language older chinese immigrant women to canada. J Cancer Educ. 2011 Mar;26(1):161-9.

86. Pati S, Feemster KA, Mohamad Z, Fiks A, Grundmeier R, Cnaan A. Maternal health literacy and late initiation of immunizations among an inner-city birth cohort. Matern Child Health J. 2011 Apr;15(3):38694.

87. Schapira MM, Neuner J, Fletcher KE, Gilligan MA, Hayes E, Laud P. The relationship of health numeracy to cancer screening. J Cancer Educ. 2011 Mar;26(1):103-10. 
TABLES AND FIGURES (listed by order of appearance in manuscript)

\section{Table 1: Inclusion/Exclusion Criteria}

\section{Population of interest Patients and caregivers of all ethnicities}

Intervention

Comparator

Outcomes

Time allowed for outcomes to appear

Time searched

Study designs allowed
Measurement of health literacy/numeracy using subjective tool Measurement of health literacy/numeracy using objective tool

Any relevant health outcomes, including utilization of health services and disease specific health outcomes, by level of health literacy/numeracy (exclusion: health knowledge as outcome)

Any (including cross-sectional data)

Since latest AHRQ review (01/01/2011) to search date (02/26/13)

RCTs, other clinical trials, case control, cohort studies, cross-sectional studies. No case reports or case series $(\mathrm{n}<10)$. 
Table 2: MEDLINE Search String ${ }^{3}$

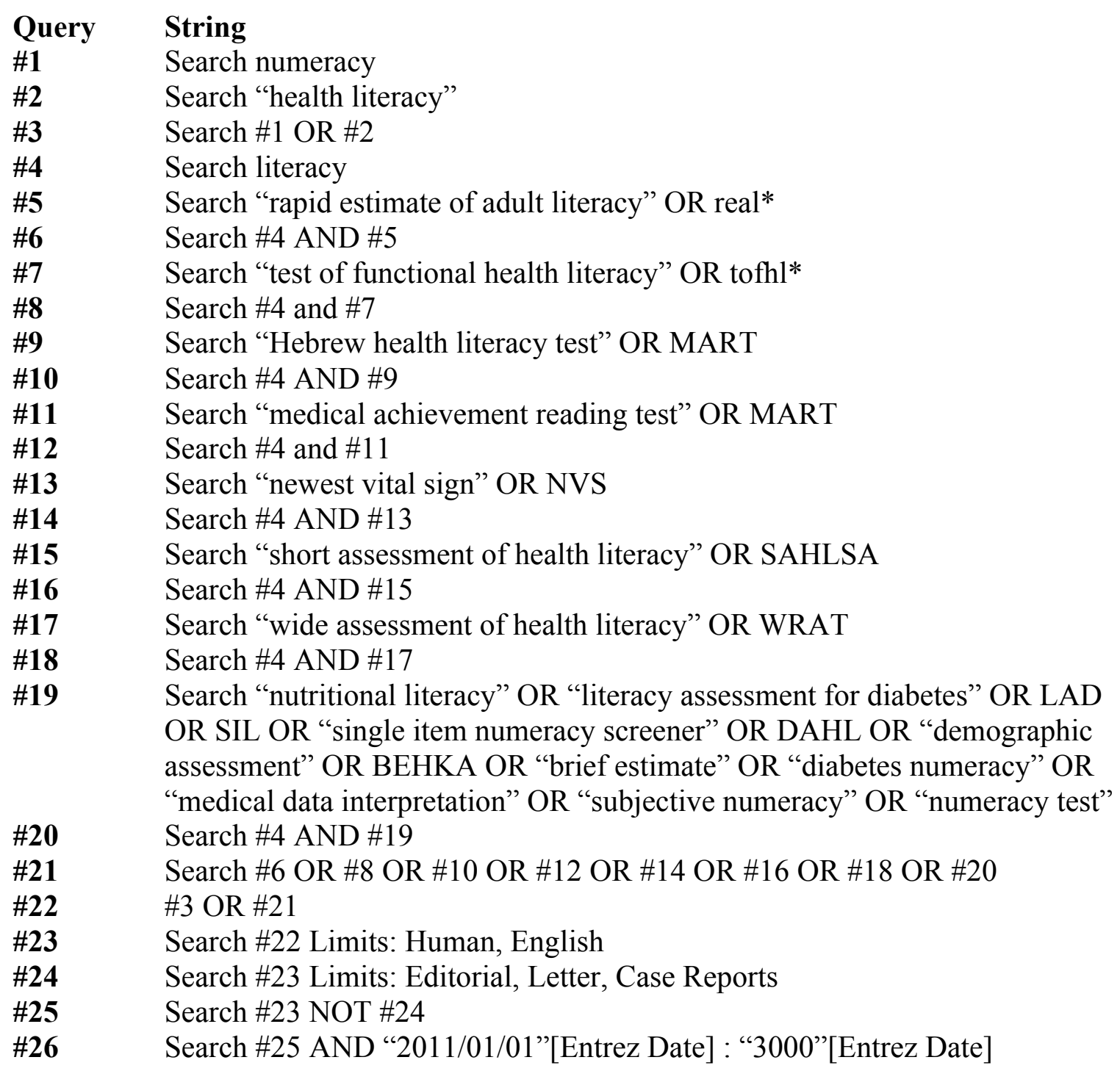

Total Hits: 878 results 


\section{Figure 1: PRISMA Flow Diagram}

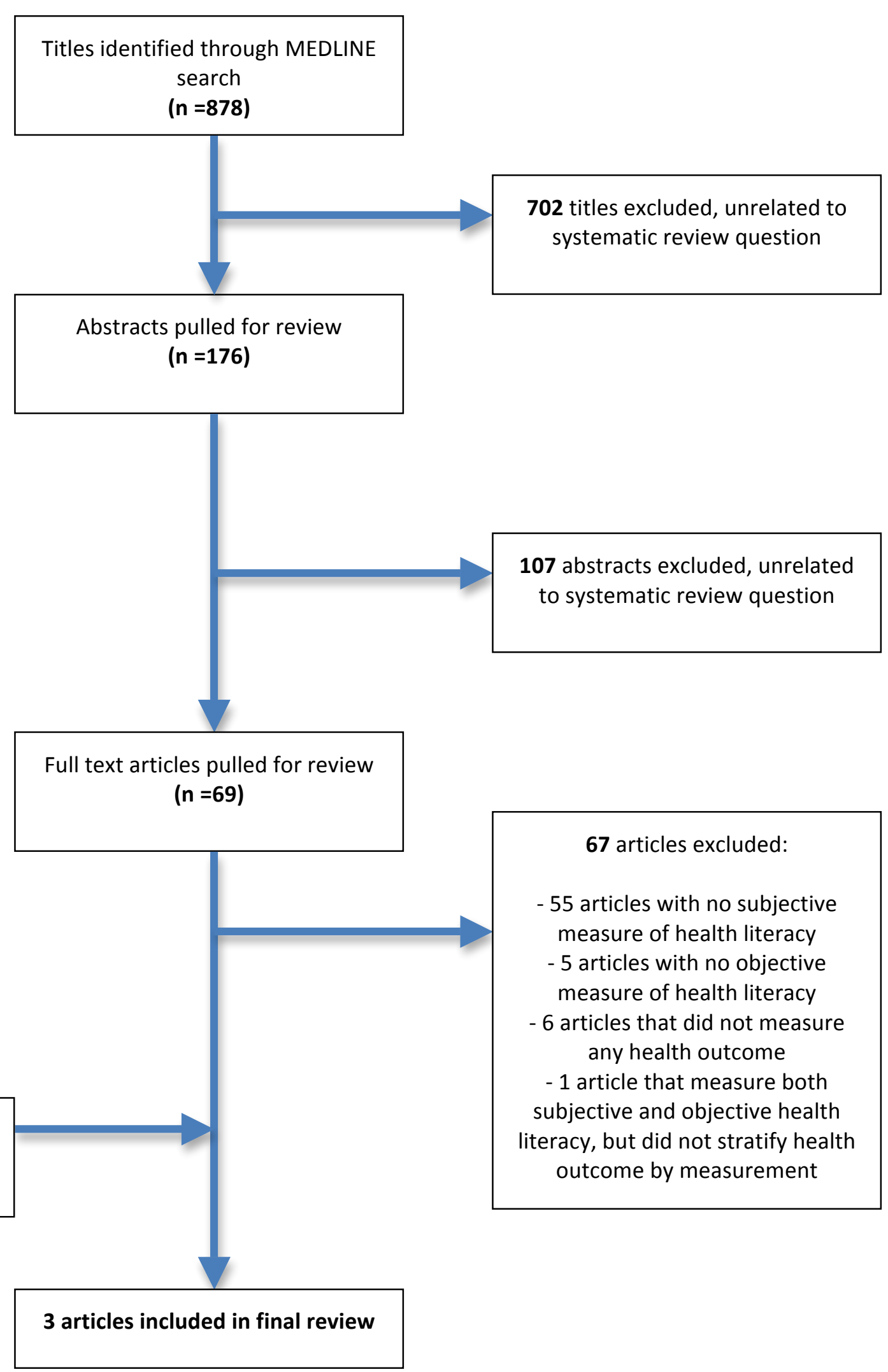


Table 3: Full Text Article Inclusions/Exclusions (sorted by latest publication date in Pubmed)

\begin{tabular}{|c|c|c|c|c|}
\hline First Author & Year & Journal & Title & Included/Excluded \\
\hline Altsitsiadis $^{22}$ & 2012 & British Journal of Dermatology & $\begin{array}{l}\text { Health literacy, sunscreen and sunbed use: an uneasy } \\
\text { association }\end{array}$ & Excluded - no objective measure of health literacy \\
\hline Mitchell $^{23}$ & 2012 & Journal of Health Communication & $\begin{array}{c}\text { Health Literacy and 30-Day Postdischarge Hospital } \\
\text { Utilization }\end{array}$ & Excluded - no subjective measure of health literacy \\
\hline Boxell $^{24}$ & 2012 & $\begin{array}{l}\text { Journal of Health Communication: } \\
\text { International Perspectives }\end{array}$ & $\begin{array}{c}\text { Increasing Awareness of Gynecological Cancer } \\
\text { Symptoms and Reducing Barriers to Medical Help } \\
\text { Seeking: Does Health Literacy Play a Role? }\end{array}$ & Excluded - no subjective measure of health literacy \\
\hline Arnold $^{25}$ & 2012 & $\begin{array}{c}\text { Journal of Health Communication: } \\
\text { International Perspectives }\end{array}$ & $\begin{array}{c}\text { Literacy Barriers to Colorectal Cancer Screening in } \\
\text { Community Clinics }\end{array}$ & Excluded - no subjective measure of health literacy \\
\hline Mosher $^{26}$ & 2012 & $\begin{array}{l}\text { Journal of Health Communication: } \\
\text { International Perspectives }\end{array}$ & $\begin{array}{c}\text { Association of Health Literacy With Medication } \\
\text { Knowledge, Adherence, and Adverse Drug Events } \\
\text { Among Elderly Veterans } \\
\end{array}$ & Excluded - no subjective measure of health literacy \\
\hline Haun $^{14}$ & 2012 & $\begin{array}{l}\text { Journal of Health Communication: } \\
\text { International Perspectives }\end{array}$ & $\begin{array}{c}\text { Measurement Variation Across Health Literacy } \\
\text { Assessments: Implications for Assessment Selection in } \\
\text { Research and Practice }\end{array}$ & Included \\
\hline Shaw $^{27}$ & 2012 & $\begin{array}{l}\text { Journal of Health Communication: } \\
\text { International Perspectives }\end{array}$ & $\begin{array}{c}\text { Chronic Disease Self-Management and Health Literacy in } \\
\text { Four Ethnic Groups }\end{array}$ & Excluded - no subjective measure of health literacy \\
\hline Rademakers $^{28}$ & 2012 & BMC Public Health & $\begin{array}{c}\text { Measuring patient activation in the Netherlands: } \\
\text { translation and validation of the American short form } \\
\text { Patient Activation Measure (PAM13) }\end{array}$ & Excluded - no health outcomes discussed \\
\hline Penaranda ${ }^{29}$ & 2012 & Southern Medical Journal & $\begin{array}{l}\text { Evaluation of Health Literacy among Spanish-Speaking } \\
\text { Primary Care Patients Along the USYMexico Border }\end{array}$ & Excluded - no subjective measure of health literacy \\
\hline Noureldin $^{30}$ & 2012 & Pharmacotherapy & $\begin{array}{c}\text { Effect of Health Literacy on Drug Adherence in Patients } \\
\text { with Heart Failure }\end{array}$ & Excluded - no subjective measure of health literacy \\
\hline Garrett $^{31}$ & 2012 & California Dental Association Journal & $\begin{array}{l}\text { Parental Functional Health Literacy Relates to Skip } \\
\text { Pattern Questionnaire Error and to Child Oral Health }\end{array}$ & Excluded - no subjective measure of health literacy \\
\hline Coffman $^{32}$ & 2012 & Journal of Cultural Diversity & $\begin{array}{c}\text { Diabetes Symptoms, Health Literacy, and Health Care } \\
\text { Use in Adult Latinos with Diabetes Risk Factors }\end{array}$ & Excluded - no subjective measure of health literacy \\
\hline Hudon $^{33}$ & 2012 & BMC Family Practice & $\begin{array}{c}\text { The relationship between literacy and multimorbidity in a } \\
\text { primary care setting }\end{array}$ & Excluded - no subjective measure of health literacy \\
\hline Bostock $^{34}$ & 2012 & British Medical Journal & $\begin{array}{l}\text { Association between low functional health literacy and } \\
\text { mortality in older adults: longitudinal cohort study }\end{array}$ & Excluded - no subjective measure of health literacy \\
\hline McCarthy $^{35}$ & 2012 & Medical Care & $\begin{array}{c}\text { What Did the Doctor Say? Health Literacy and Recall of } \\
\text { Medical Instructions }\end{array}$ & Excluded - no subjective measure of health literacy \\
\hline Huang $^{36}$ & 2012 & $\begin{array}{c}\text { Clinical Gastroenterology and } \\
\text { Hepatology }\end{array}$ & $\begin{array}{c}\text { Clinicians Poorly Assess Health Literacy-Related } \\
\text { Readiness for Transition to Adult Care in Adolescents } \\
\text { With Inflammatory Bowel Disease } \\
\end{array}$ & Excluded - no health outcomes discussed \\
\hline Vassy $^{38}$ & 2012 & Medical Decision Making & $\begin{array}{l}\text { Impact of Literacy and Numeracy on Motivation for } \\
\text { Behavior Change After Diabetes Genetic Risk Testing }\end{array}$ & Excluded - no subjective measure of health literacy \\
\hline
\end{tabular}




\begin{tabular}{|c|c|c|c|c|}
\hline Bains $^{39}$ & 2011 & $\begin{array}{c}\text { Complementary and Alternative } \\
\text { Medicine }\end{array}$ & $\begin{array}{c}\text { Association of Health Literacy with Complementary and } \\
\text { Alternative Medicine Use: A Cross-Sectional Study in } \\
\text { Adult Primary Care } \\
\end{array}$ & Excluded - no subjective measure of health literacy \\
\hline $\operatorname{Rosman}^{40}$ & 2012 & Pediatric Emergency Care & $\begin{array}{l}\text { Predictors of Prescription Filling After Visits to the } \\
\text { Pediatric Emergency Department }\end{array}$ & Excluded - no subjective measure of health literacy \\
\hline McDougall $^{41}$ & 2012 & Nursing Research & $\begin{array}{l}\text { Memory Performance, Health Literacy, and Instrumental } \\
\text { Activities of Daily Living of Community Residing Older } \\
\text { Adults }\end{array}$ & Excluded - no subjective measure of health literacy \\
\hline Backes ${ }^{42}$ & 2012 & $\begin{array}{c}\text { Research in Social and Administrative } \\
\text { Pharmacy }\end{array}$ & $\begin{array}{c}\text { The association between functional health literacy and } \\
\text { patient-reported recall of medications at outpatient } \\
\text { pharmacies }\end{array}$ & Excluded - no subjective measure of health literacy \\
\hline Cappelletti ${ }^{43}$ & 2012 & Neuropsychology & $\begin{array}{c}\text { Numeracy Skills in Patients With Degenerative Disorders } \\
\text { and Focal Brain Lesions: A Neuropsychological } \\
\text { Investigation }\end{array}$ & Excluded - no subjective measure of health literacy \\
\hline Smith $^{44}$ & 2012 & Maternal and Child Health Journal & $\begin{array}{c}\text { Health Literacy and Depression in the Context of Home } \\
\text { Visitation }\end{array}$ & Excluded - no objective measure of health literacy \\
\hline Kirk $^{45}$ & 2011 & Journal of General Internal Medicine & $\begin{array}{c}\text { Performance of Health Literacy Tests Among Older } \\
\text { Adults with Diabetes }\end{array}$ & Excluded - no subjective measure of health literacy \\
\hline McNaughton $^{18}$ & 2011 & Academic Emergency Medicine & $\begin{array}{c}\text { Short, Subjective Measures of Numeracy and General } \\
\text { Health Literacy in an Adult Emergency Department }\end{array}$ & Excluded - no health outcomes discussed \\
\hline Robinson $^{46}$ & 2011 & Journal of Cardiac Failure & Assessing Health Literacy in Heart Failure Patients & Excluded - no subjective measure of health literacy \\
\hline $\mathrm{Lee}^{47}$ & 2012 & American Journal of Public Health & $\begin{array}{l}\text { The Relationship of Oral Health Literacy and Self- } \\
\text { Efficacy With Oral Health Status and Dental Neglect }\end{array}$ & Excluded - no subjective measure of health literacy \\
\hline Jeppesen $^{48}$ & 2011 & Journal of General Internal Medicine & $\begin{array}{c}\text { A Validation Study of the Spoken Knowledge in Low } \\
\text { Literacy in Diabetes Scale (SKILLD) }\end{array}$ & Excluded - no subjective measure of health literacy \\
\hline Martin $^{49}$ & 2012 & $\begin{array}{l}\text { Journal of Epidemiology of Community } \\
\text { Health }\end{array}$ & Which literacy skills are associated with smoking? & Excluded - no subjective measure of health literacy \\
\hline $\operatorname{Marden}^{50}$ & 2011 & Diabetic Medicine & $\begin{array}{l}\text { Poor numeracy skills are associated with glycaemic } \\
\text { control in Type } 1 \text { diabetes }\end{array}$ & Excluded - no subjective measure of health literacy \\
\hline Lindquist ${ }^{51}$ & 2011 & Journal of General Internal Medicine & $\begin{array}{c}\text { Relationship of Health Literacy to Intentional and } \\
\text { Unintentional Non-Adherence of Hospital Discharge } \\
\text { Medications }\end{array}$ & Excluded - no subjective measure of health literacy \\
\hline Hardie $^{52}$ & 2011 & Journal of Health Communication & $\begin{array}{l}\text { Health Literacy and Health Care Spending and Utilization } \\
\text { in a Consumer-Driven Healh Plan }\end{array}$ & Excluded - no objective measure of health literacy \\
\hline Rubin $^{53}$ & 2011 & Journal of Health Communication & $\begin{array}{c}\text { Associations Between Older Adults' Spoken Interactive } \\
\text { Health Literacy and Selected Health Care and Health } \\
\text { Communication Outcomes } \\
\end{array}$ & Excluded - no subjective measure of health literacy \\
\hline Telford $^{54}$ & 2012 & American Journal of Public Health & $\begin{array}{c}\text { Physical Education, Obesity, and Academic } \\
\text { Achievement: A 2-Year Longitudinal Investigation of } \\
\text { Australian Elementary School Children } \\
\end{array}$ & Excluded - no subjective measure of health literacy \\
\hline Omariba $^{55}$ & 2011 & Canadian Journal of Public Health & $\begin{array}{l}\text { Immigration, Generation, and Self-Rated Health in } \\
\text { Canada: On the Role of Health Literacy }\end{array}$ & Excluded - no subjective measure of health literacy \\
\hline Fernandez ${ }^{56}$ & 2011 & Implementation Science & The counseling african americans to control hypertension & Excluded - no subjective measure of health literacy \\
\hline
\end{tabular}




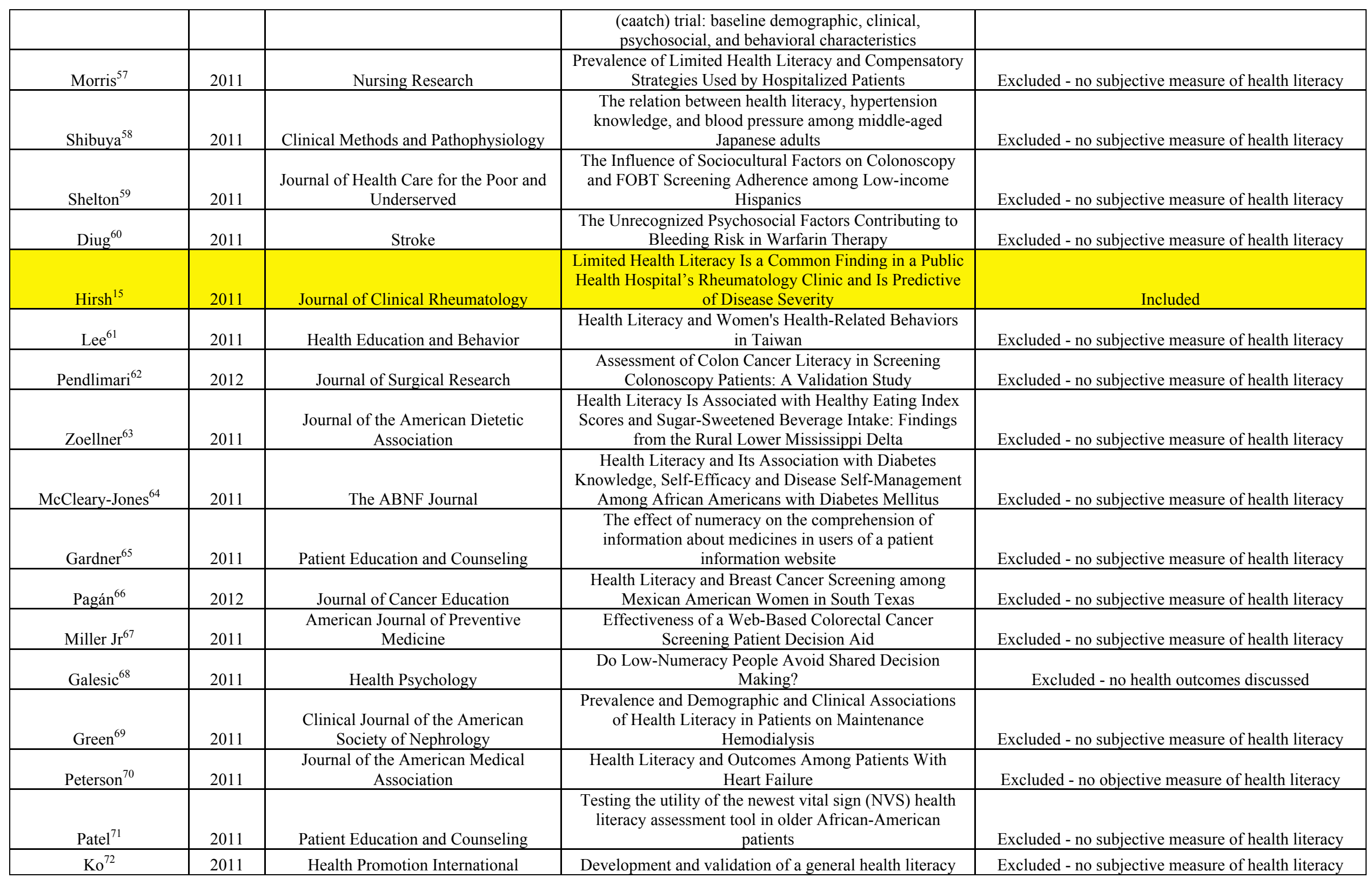




\begin{tabular}{|c|c|c|c|c|}
\hline & & & test in Singapore & \\
\hline Begoray $^{73}$ & 2011 & Health Promotion International & $\begin{array}{c}\text { A Canadian exploratory study to define a measure of } \\
\text { health literacy }\end{array}$ & Excluded - no health outcomes discussed \\
\hline Ishikawa $^{74}$ & 2011 & Patient Education and Counseling & $\begin{array}{l}\text { The relationship of patient participation and diabetes } \\
\text { outcomes for patients with high vs. low health literacy }\end{array}$ & Excluded - no objective measure of health literacy \\
\hline $\begin{array}{l}\text { Macabasco- } \\
\text { O'Connell }^{75}\end{array}$ & 2011 & Journal of General Internal Medicine & $\begin{array}{c}\text { Relationship Between Literacy, Knowledge, Self-Care } \\
\text { Behaviors, and Heart Failure-Related Quality of Life } \\
\text { Among Patients With Heart Failure }\end{array}$ & Excluded - no subjective measure of health literacy \\
\hline Chaudhry ${ }^{76}$ & 2011 & Journal of Cardiac Failure & $\begin{array}{l}\text { Racial Disparities in Health Literacy and Access to Care } \\
\text { Among Patients With Heart Failure }\end{array}$ & Excluded - no subjective measure of health literacy \\
\hline Bains $^{77}$ & 2011 & Diabetes Technology and Therapeutics & $\begin{array}{l}\text { Associations between Health Literacy, Diabetes } \\
\text { Knowledge, Self-Care Behaviors, and Glycemic Control } \\
\text { in a Low Income Population with Type } 2 \text { Diabetes }\end{array}$ & Excluded - no subjective measure of health literacy \\
\hline $\mathrm{Chen}^{78}$ & 2011 & Journal of Cardiovascular Nursing & $\begin{array}{l}\text { Health Literacy and Self-care of Patients With Heart } \\
\text { Failure }\end{array}$ & Excluded - no subjective measure of health literacy \\
\hline Naik $^{79}$ & 2011 & Patient Education and Counseling & $\begin{array}{l}\text { Health literacy and decision making styles for complex } \\
\text { antithrombotic therapy among older multimorbid adults }\end{array}$ & Excluded - no health outcomes discussed \\
\hline Lindquist ${ }^{80}$ & 2010 & Journal of General Internal Medicine & $\begin{array}{l}\text { Inadequate Health Literacy Among Paid Caregivers of } \\
\text { Seniors }\end{array}$ & Excluded - no subjective measure of health literacy \\
\hline Sarkar $^{82}$ & 2010 & Journal of General Internal Medicine & $\begin{array}{c}\text { Validation of Self-Reported Health Literacy Questions } \\
\text { Among Diverse English and Spanish-Speaking } \\
\text { Populations }\end{array}$ & $\begin{array}{l}\text { Excluded - health outcome not stratified by objective } \\
\text { vs subjective measure }\end{array}$ \\
\hline Osborn $^{83}$ & 2011 & American Journal of Health Behavior & $\begin{array}{c}\text { The Mechanisms Linking Health Literacy to Behavior } \\
\text { and Health Status }\end{array}$ & Excluded - no subjective measure of health literacy \\
\hline Martin $^{84}$ & 2010 & Journal of General Internal Medicine & $\begin{array}{c}\text { Literacy Skills and Calculated 10-Year Risk of Coronary } \\
\text { Heart Disease }\end{array}$ & Excluded - no subjective measure of health literacy \\
\hline Todd $^{85}$ & 2010 & Journal of Cancer Education & $\begin{array}{c}\text { Predicting Breast and Colon Cancer Screening Among } \\
\text { English-as-a-Second-Language Older Chinese Immigrant } \\
\text { Women to Canada }\end{array}$ & Excluded - no subjective measure of health literacy \\
\hline Pati $^{86}$ & 2011 & Maternal and Child Health Journal & $\begin{array}{l}\text { Maternal Health Literacy and Late Initiation of } \\
\text { Immunizations Among an Inner-City Birth Cohort }\end{array}$ & Excluded - no subjective measure of health literacy \\
\hline Schapira ${ }^{87}$ & 2011 & Journal of Cancer Education & $\begin{array}{c}\text { The Relationship of Health Numeracy to Cancer } \\
\text { Screening }\end{array}$ & Excluded - no subjective measure of health literacy \\
\hline
\end{tabular}


Table 4: Characteristics of Included Studies

\begin{tabular}{|c|c|c|c|c|c|}
\hline Study & Design & $\begin{array}{c}\text { Objective } \\
\text { Measure }\end{array}$ & $\begin{array}{c}\text { Subjective } \\
\text { Measure }\end{array}$ & $\begin{array}{c}\text { Health } \\
\text { Outcome }\end{array}$ & Setting \\
\hline Haun $^{14}$ & $\begin{array}{l}\text { Cross- } \\
\text { sectional } \\
\text { paper survey }\end{array}$ & $\begin{array}{l}\text { S-TOFHLA } \\
\text { REALM }\end{array}$ & BRIEF & $\begin{array}{l}\text { Three } \\
\text { dichotomous } \\
\text { health } \\
\text { questions } \\
\text { (diabetes, } \\
\text { hypertension, } \\
\text { past stroke) }\end{array}$ & $\begin{array}{l}\text { Ambulatory } \\
\text { clinics in } \\
\text { rural and non- } \\
\text { rural VA } \\
\text { medical } \\
\text { facilities }\end{array}$ \\
\hline $\operatorname{Hirsh}^{15}$ & $\begin{array}{l}\text { Cross- } \\
\text { sectional } \\
\text { paper survey }\end{array}$ & $\begin{array}{l}\text { S-TOFHLA } \\
\text { REALM }\end{array}$ & SILS & $\begin{array}{l}\text { DAS-28 } \\
\text { MDHAQ }\end{array}$ & $\begin{array}{l}\text { Adult } \\
\text { rheumatology } \\
\text { clinic at } \\
\text { Denver } \\
\text { Health }\end{array}$ \\
\hline Ciampa $^{6}$ & $\begin{array}{l}\text { Cross- } \\
\text { sectional } \\
\text { paper and } \\
\text { phone based } \\
\text { survey }\end{array}$ & $\begin{array}{l}1 \text { item from } \\
\text { Schwartz and } \\
\text { Woloshint }\end{array}$ & $\begin{array}{l}1 \text { item from } \\
\text { Lipkus et } \\
\text { al. } \star\end{array}$ & $\begin{array}{l}\text { Use of } \\
\text { screening } \\
\text { services }\end{array}$ & $\begin{array}{l}\text { Nationally } \\
\text { representative } \\
\text { survey of } \\
\text { cancer } \\
\text { knowledge, } \\
\text { attitudes and } \\
\text { behaviors }\end{array}$ \\
\hline
\end{tabular}

†: "In general, how hard or easy do you find it to understand medical statistics?"

$\star:$ "Which of the following numbers represents the biggest risk of getting a disease, 1 in 100, 1 in 1000 or 1 in $10 ?^{8}$ 


\title{
Comparison of Brief Health Literacy Screens in the Emergency Department
}

\begin{abstract}
Background: A fast way of measuring health literacy is of great interest both clinically and in research but there are many tools available. The objective was to determine the capacity of five brief health literacy screening tools to predict the results of the longer Short Test of Functional Health Literacy in Adults (S-TOFHLA) in an adult emergency department (ED) setting.
\end{abstract}

Methods: A sample of 400 adult ED patients was enrolled in two equal blocks ensuring equal representation of higher and lower educational levels. These patients completed the S-TOFHLA as a referent standard, as well as the Newest Vital Sign (NVS), Single Item Literacy Screen (SILS), brief validated screening questions, Rapid Estimate of Adult Literacy in Medicine Revised (REALM-R) and the Medical Term Recognition Test (METER). These patients also completed a demographic survey and answered some questions about their health. Validity of the brief screening tools against the S-TOFHLA was assessed using Spearman's correlation coefficients, receiver operating characteristics (ROC) curves and by calculating test characteristics (sensitivity, specificity, likelihood ratios) at different test cutoffs.

Results: The enrolled sample of 400 patients was on average approximately 38 years old. Approximately 58\% were female, 63\% were Caucasian and 30\% were African American. Most patients had adequate health literacy as measured by the S-TOFHLA (93\% adequate, median score of 35, IQR 32-35). Using the brief screening tools, a range of 52\% (NVS) to $81 \%$ (brief screening question about help with medical materials) had adequate health literacy. All brief tests were significantly correlated with the S-TOFHLA $(\mathrm{p}<0.001)$, with the REALM-R, METER and NVS having greater Spearman's correlation coefficients $(r=0.56,0.53$ and 0.62 , respectively) 
than the self-reported measures. The greatest area under the ROC curve (AUROC) was obtained for the NVS (AUROC $=0.89,95 \%$ CI $0.85-0.94$ ) while the lowest AUROC was found for the brief screening question about problems with medical materials (AUROC $=0.75,95 \%$ CI 0.65 0.85). The sensitivities and specificities for each test indicated some alternative cutpoints that could be considered depending on the purpose of screening. In our sample, those with adequate health literacy were significantly younger, more likely to be women, Caucasian, and to speak English as a first language $(\mathrm{p}<0.05)$. They had significantly more education, better self-reported health status, and fewer ED visits $(\mathrm{p}<0.05)$.

Conclusions/Implications: Our results indicate that the NVS was best able to identify limited health literacy on the S-TOFHLA, but that all tools performed well enough at this task to be considered as a substitute. Our data indicate widespread differences in the characteristics of these tests beyond their ability to predict the S-TOFHLA literacy categorization, including the proportion of patients characterized as having limited health literacy, their administration characteristics and the skill sets that they target. Future research will need to determine their specific strengths and weaknesses in predicting outcomes. In the mean time, researchers and clinicians alike should think carefully about which tool to use based on the specific skills being targeted, intent of screening, and resource availability. 


\section{INTRODUCTION}

Health literacy is the capacity to obtain, process and understand basic health information services needed to make the appropriate health decisions. ${ }^{1}$ Unfortunately, low health literacy is a significant problem in the United States (US). The 2003 U.S. Department of Education national assessment of adult literacy showed that only $12 \%$ of surveyed adults possessed proficient health literacy, with $36 \%$ of the population falling at the below basic or basic health literacy levels. ${ }^{2}$ There is accumulating evidence connecting limited health literacy with poor health outcomes. For example, patients with limited health literacy visit emergency departments more often, are hospitalized more often, and receive fewer preventive screening services such as mammograms or influenza vaccinations. ${ }^{3}$ These patients have a harder time taking their medications appropriately, or interpreting labels and health messages. ${ }^{3}$ Overall, these patients have poorer health status and higher all-cause mortality. ${ }^{3}$

The emergency department (ED) in particular acts as a safety net for many patients with limited health literacy, ${ }^{4,5}$ and providers in this setting are often faced with stringent time constraints. Physicians tend to overestimate the health literacy of their patients when not relying on standardized tools, ${ }^{6}$ but such tools are often too time-consuming for practical use. The most commonly used standards against which other tools are validated are the Test of Functional Health Literacy in Adults (TOFHLA) and the REALM. The TOFHLA combines a 50-item reading comprehension section with a 17 -item numeracy section, and takes approximately 22 minutes to administer. ${ }^{7}$ A shorter validated version containing just 36 items from the reading comprehension component, the S-TOFHLA, still takes around 7 minutes to administer. ${ }^{8}$ The REALM test assesses pronunciation of 66 medical words and takes up to 3 minutes to 
administer, ${ }^{9,10}$ but some doubt that pronunciation can correctly identify patients with limited health literacy. ${ }^{11}$

Screening for health literacy remains controversial in a practical context, with many arguing for a universal precautions approach promoting clear communication with all patients. ${ }^{12}$ Alternatively, gaining a better understanding of current screening tools can inform interpretation of existing studies measuring health literacy, as well as selection of a tool in research contexts. Additionally, there may be a place for health literacy screening in resource and time-limited settings, and room for physicians to tailor care to their patients' literacy level. ${ }^{13,14}$ Such an approach might be particularly welcome if shorter and less embarrassing tools could be validated, removing traditional barriers to widespread screening implementation. ${ }^{12}$

Health literacy can be challenging to measure. Several brief health literacy screens have been proposed and tested in a variety of settings and hold promise as an efficient means to screen patients for health literacy problems. ${ }^{15-19}$ Some of these screens are as short as a single question, and all take under 3 minutes to administer. There is limited research concerning the reliability of these tools in the ED. ${ }^{20}$ In this study, we administered the S-TOFHLA as a referent standard and five shorter screening tools (Newest Vital Sign, Single Item Literacy Screen, validated subjective questions, REALM-R, and METER) sequentially to patients in a suburban ED to determine their differences in measuring health literacy. No studies to date have sequentially employed all these screening tools. Our secondary aim was to collect cross-sectional data about these patients' health resource utilization and examine associations with low health literacy levels. 


\section{METHODS}

\section{Setting and Sample}

This study was conducted at a southeastern US suburban adult emergency department and level I trauma center with an annual census of 75,000 patients. Data were collected by the co-investigator and two research assistants between January 2013 and May 2013. Patients deemed critically ill, decisionally impaired or intoxicated by the charge nurse or attending physician were not approached. All other patients were sequentially approached during data collection hours (weekday afternoons and evenings, and weekend evenings).

A prospectively defined sample of 400 participants was sought. We utilized block enrollment to ensure equal representation of higher (some college or more) and lower (high school diploma or GED or less) education levels. Once the block enrollment target was reached for a group, no further subjects in that educational block were enrolled.

Subjects were excluded if they were unable to hold a conversation in English, were under 18 years old, refused participation at any time, were interrupted during the timed portion of the

study (S-TOFHLA) or required corrective eyewear that they did not have with them at the time of the study. The local institutional review board approved the study. Verbal informed consent was obtained from every patient after review of an information sheet.

\section{Health Literacy Measurements}

Patients who provided informed consent were given six total tests of health literacy (STOFHLA, Newest Vital Sign [NVS], Single Item Literacy Screen [SILS], validated screening questions, REALM-R and METER, in that order). The S-TOFLHA is one of the most common tools used to measure health literacy. ${ }^{3}$ Derived from the full TOFHLA, the abbreviated test includes a condensed version of both the reading comprehension and numeracy components. In 
development, the reading passages alone correlated as well with the REALM as the complete STOFHLA. ${ }^{8}$ In our study we administered both reading passages to each patient, who had a maximum of seven minutes to choose appropriate words to fill in blanks in the medical texts. The test produces a continuous score based on the number of correct choices, from 0 to 36 . This score is often categorized into inadequate literacy (0-16), marginal literacy (17-22) and adequate literacy (23-36). For our study, inadequate and marginal literacy were merged into a single category of limited health literacy.

The Newest Vital Sign consists of a fictitious ice cream nutritional label that is handed to the patient, as the interviewer asks six questions requiring both health literacy and numeracy skills. ${ }^{15}$ The total correct answers are summed to produce a score from 0 to 6 . In the study validating the tool, a score of 0-1 suggested high likelihood of limited health literacy, a score of 2-3 indicated a possibility of limited health literacy, and a score of 4-6 almost always indicated adequate literacy. ${ }^{15}$

The Single Item Literacy Screen (SILS) was developed in 2006 following an evaluation by Chew et al. of 16 screening questions to identify inadequate health literacy in a VA hospital. ${ }^{16}$ The original study found 3 questions, each on a 5 point Likert scale, that could successfully identify these patients: one assessing confidence in filling out medical forms, one assessing need for help in reading hospital materials, and the final question assessing difficulty understanding written information in trying to learn more about a medical condition. All three questions were later validated against both the S-TOFHLA and the REALM. ${ }^{21}$ The SILS draws on this research and asks "how often do you need to have someone help you when you read instructions, pamphlets, or other written material from your doctor or pharmacy?" Both the SILS and the three original screening questions were asked sequentially. The screening questions were considered 
both individually, and as a composite sometimes referred to as the Short Literacy Survey (SLS), in which all three scores (from 1 to 5 per question) are added after reversing the help and problem questions such that the highest scores indicate higher subjective health literacy, producing a score from 3 to $15 .^{22}$

The REALM-R is a shortened version of the full REALM test, assessing pronunciation of 8 words instead of 66 (allergic, jaundice, anemia, fatigue, directed, colitis, constipation and osteoporosis) and taking 1 minute to complete and score. A score of 6 or fewer correctly pronounced words correctly identified 26 of 30 patients reading at a sixth grade level in the study that introduced the test. ${ }^{19}$

The Medical Term Recognition Test (METER) contains a list of 40 medical words mixed in with nonwords. The patient is required to identify the real words by putting a mark next to them on a sheet of paper. Many of the words are the same as the words on the REALM test, and the study first describing the tool was found to correlate highly with the latter. ${ }^{17}$ In our study, the METER was scored by simply totaling the amount of real words correctly identified, an approach shown in its validating study to be highly similar and faster to score compared to an alternative scoring approach which penalizes nonwords identified as real words. ${ }^{17}$

\section{Other Variables}

In the enrollment phase of the study, sex, age, race, preferred spoken language and highest education level achieved were measured among both study completers and those who declined participation or were ineligible. Among study completers, further information was collected after the literacy tests. These variables included self-described health status (Likert scale), number of daily medications, number of ED visits in last 12 months, identification of one 
doctor as "primary care physician", and number of primary care visits in last 12 months if a primary care doctor was identified.

Analysis

Data analysis was conducting using Stata version 12 (StataCorp, College Station, TX). We describe the characteristics of the full sample, and stratified these characteristics by completion status (comparing study completers to refusals and exclusions) using the chi-square and Student $t$ test to detect differences in those samples for categorical and continuous variables respectively. The same tests were used to find differences in the characteristics of patients with adequate and limited health literacy as defined by the STOFHLA. In these analyses, race was consolidated for categories with 5 or fewer subjects (Asian/Pacific Islander [n=5], Native American [n=3], Southeast Asian/Indian Subcontinent [n=3], Other [n=2]) into an other category.

Spearman's rank correlation coefficient was calculated for each brief screening test (NVS, SILS, SLS, screening questions, REALM-R and METER) to determine statistical dependence with the S-TOFHLA. For these calculations, all these variables were treated as continuous.

Using limited health literacy on the S-TOFHLA as the comparison standard (score of 22 or less), nonparametric receiver operating characteristic (ROC) curves were created for the NVS, SILS, SLS, individual screening questions, REALM-R and METER to determine the area under the ROC curves (AUROC), and sensitivities and specificities at each cutoff point for predicting low health literacy. 


\section{RESULTS}

A total of 700 patients were approached between January 2013 and May 2013, of whom 400 provided consent and completed the study. Reasons for non-completion among the 300 other patients included not being comfortable holding a conversation in English (43 patients), not providing consent or deciding to stop the study prematurely (173 patients), being interrupted during the timed portion of the study (4 patients), needing corrective eyewear and not having it available in the ED (26 patients) and after filling up the first enrollment block, exclusion based on educational status (68 patients). These were not mutually exclusive, and as such total more than 300 patients.

Patients enrolled in the study were on average approximately 38 years old (Table 1). Approximately 58\% were female, 63\% were Caucasian, and 30\% were African American. The preferred spoken language of the vast majority was English (96\%). Compared to patients who did not consent or qualify for the study, patients enrolled were younger $(p<0.01)$, less diverse (fewer African American and Latino subjects enrolled, $\mathrm{p}<0.01$ ), and preferred to speak English $(p<0.01)$. Despite excluding 68 subjects because of higher educational achievement in the later part of the study, patients enrolled still had a significantly higher education level than those not enrolled $(\mathrm{p}<0.01)$

The proportion of patients deemed to have adequate health literacy varied widely based on tool selection (Table 2). Using the S-TOFHLA and condensing inadequate and marginal literacy into limited health literacy, $92.5 \%$ of the sample had adequate health literacy. Using the NVS and similarly condensing categories, just $52 \%$ of patients were found to have adequate health literacy. Using the cutoff of $>2$ (more than rarely) suggested in the validation of the SILS, $75 \%$ had adequate health literacy. Similarly, using a cutoff of $>2$ (more than occasionally) for the 
help question and the problems question, $80.5 \%$ and $76.8 \%$ of the sample, respectively, had adequate health literacy. Using the confidence question with a cutoff of often or more (often or always confident filling out medical forms), $75.3 \%$ had adequate health literacy. There is no accepted cutoff for the Short Literacy Survey which combines these three questions. Using the suggested REALM-R score of 6 or less as a cutoff, $64 \%$ of our sample had adequate health literacy. Finally, using the METER's suggested cutoff of $\geq 35$ correctly identified words, $79 \%$ of the sample had adequate health literacy.

The Spearman's rank correlations shown in Table 2 show that all screening tools used are significantly correlated with the S-TOFHLA. The sensitivities and specificities for different cutoffs of each screening tool are shown in Table 3. When available, suggested cutoff points are shown in bold within the table. Figures 1 through 8 show the corresponding nonparametric Receiver Operating Characteristic (ROC) curves for these tools based on these same cutoffs. Combining the three screening questions into the Short Literacy Survey moderately increases the area under the ROC curve (AUROC) to 0.82 ( $95 \%$ CI $0.73-0.91)$, but not significantly more than the individual questions. The largest AUROC was seen for the NVS $(0.89,95 \%$ CI 0.85 $0.94)$.

The characteristics of patients deemed to have limited (inadequate/marginal) health literacy on the S-TOFHLA compared to the patients with adequate health literacy on the STOFHLA are summarized in Table 4. Patients with limited health literacy were significantly older (mean of 50.0 years, compared to 37.4 years among adequate cohort, $\mathrm{p}<0.01$ ), and more commonly men ( $60 \%$ of limited cohort, compared to $41 \%$ of adequate cohort, $\mathrm{p}=0.04)$. Those with limited health literacy were more likely to be Latino or African American ( $\mathrm{p}<0.01)$, and less likely to identify English as their preferred language $(\mathrm{p}<0.01)$. Lower levels of educational 
attainment were significantly associated with limited health literacy $(\mathrm{p}<0.01)$. Patients with limited health literacy were more likely to have lower self-rated health statuses (poor or fair, $\mathrm{p}<0.01$ ), and had significantly more ED visits ( 4.0 vs $2.8, \mathrm{p}=0.04$ ). There was a suggestion of a difference in rates of primary care access, but this was not statistically significant $(\mathrm{p}=0.08)$.

\section{DISCUSSION}

Because of its associations with negative health outcomes, ${ }^{3}$ mitigating the effects of low health literacy must be a priority, and accurately identifying those with limited skills is an important first step. In our ED sample, $7.5 \%$ of patients were deemed to have inadequate or marginal health literacy as measured by the S-TOFHLA. This percentage is lower than was reported in a multicenter study of limited health literacy in Boston Emergency Departments

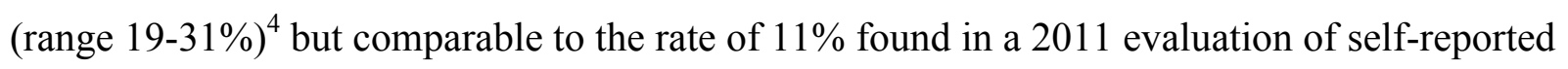
measures of health literacy in an urban ED. ${ }^{20}$ The characteristics of the patients enrolled compared to those who refused or were excluded (Table 1) show a number of significant associations (younger, less ethnically diverse, more educated and preferring to speak English) which were all associated with higher health literacy in our analyses (Table 4). This selection bias would lead to an underestimation of the true prevalence of limited health literacy in our study ED.

Our primary aim was to compare many brief measures of health literacy to the STOFHLA in a single population. Our findings indicate that the NVS, REALM-R and METER are well correlated with the S-TOFHLA and that the self-reported questions (SILS, and three validated questions) are moderately correlated with the S-TOFHLA.

Our results show that tool selection greatly affects the proportion of subjects deemed to have limited health literacy. The referent standard (S-TOFHLA) classified the fewest subjects in 
this category at $7.5 \%$ while the REALM-R (36\%) and the NVS (48\%) classified the most subjects as limited. All the self-reported tools, as well as the METER, classified 20-25\% of subjects as limited in health literacy using the suggested cutoffs. Other studies that have used multiple tools to measure health literacy have reported similar differences in classification, with the S-TOFHLA often classifying fewer people as having limited health literacy. ${ }^{23-25}$ This raises a significant question: while the S-TOFHLA and full REALM are most often used as referent standards, ${ }^{3}$ new instruments are validated against these older tools and may in fact be measuring separate constructs ${ }^{26}$ or more effectively identifying at-risk individuals. Depending on the purpose and setting of health literacy screening, or the specific skill set targeted, different tools may be more appropriate. ${ }^{24,27}$

The NVS had the best ability to predict limited health literacy on the S-TOFHLA of the short screening tools, with an AUROC of 0.89 (95\% CI $0.85-0.94)$, similar to past validation studies. ${ }^{15,28}$ Using the suggested cutoff of $\leq 3$, the NVS had a sensitivity of $97 \%$ and a specificity of $56 \%$. Changing the cutoff to $\leq 3$, a small drop in sensitivity could be achieved $(93 \%)$ for a large gain in sensitivity (69\%), and this cutoff could be used to reduce the rate of false positives depending on the prevalence of limited health literacy in a given setting. The NVS appears to be a suitable substitute for the S-TOFHLA in our ED environment. The NVS is more reliant on numeracy skills than other health literacy screening tools ${ }^{26}$ and past research has shown that among patients with low literacy, numeracy and literacy do not correlate in $40 \%$ of adults. ${ }^{29}$ If these constructs are being specifically or separately targeted, the NVS may not be appropriate. In an older African-American cohort, NVS's utility as a brief screening tool was questioned because it took an average of 11 minutes to complete. ${ }^{30}$ Though we did not time the length of administration in our study, all three data collectors $(\mathrm{EK}, \mathrm{AH}, \mathrm{KN})$ noted that the time of 
administration of the NVS often exceeded the 2.9 minutes reported in the original study ${ }^{15}$ and seemed to cause more embarrassment and frustration in patients than the other tools. While the NVS did not take as long to administer as the S-TOFHLA in our study, it took longer than the REALM-R, METER, or self-reported measures. Time constraints may come into play in deciding whether or not to use the NVS for screening.

The self-reported measures performed the least well in our evaluation, with AUROCs ranging from 0.75 for the problems question to 0.80 for the help question. This is consistent with prior research, which has shown variable effectiveness, with AUROCs ranging from 0.60 to 0.81. ${ }^{18,21,31}$ Using the suggested cutoffs on these items led to moderate sensitivity $(77 \%-83 \%)$ but lower specificities (58\% to $71 \%$ ). The SLS scale summing the answers to the questions led to a greater AUROC $(0.82,95 \%$ CI $0.73-0.91)$ than any individual question, though this was not statistically significant. The SLS provides some flexibility, depending on the cutoff used and the characteristics of the setting. Sensitivity can be maximized $(90 \%$ using a cutoff of $\leq 14)$, or a trade-off can be achieved ( $80 \%$ sensitive and $77 \%$ specific at a cutoff of $\leq 11)$ while maintaining the advantages of the self-administered items: rapid administration $(<1$ minute $)$, diminished potential for embarrassment ${ }^{16}$ and ability to be administered over the phone or by mail survey. ${ }^{24}$

The REALM-R performed well in detecting limited health literacy on the S-TOFHLA, with the second highest AUROC after the S-TOFHLA (0.84, 95\% CI 0.77-0.92). No studies to date have compared these tools. Our results suggest a possible advantage to a cutoff of $\leq 5$ from $\leq 6$, increasing specificity from $68 \%$ to $79 \%$ at the expense of a small drop in sensitivity from $83 \%$ to $80 \%$. The REALM-R may provide a better indication of verbal communication skills than the other tools, ${ }^{24}$ and is the fastest performance-based tool that was tested, usually taking under a minute to administer. 
The METER performed similarly to the REALM-R in predicting limited health literacy on the S-TOFHLA, unsurprisingly since it was developed from the list of REALM words. ${ }^{17}$ The suggested cutoff of $\leq 34$ was $77 \%$ sensitive and $84 \%$ specific for identifying limited health literacy, though cutoffs of $\leq 35, \leq 36$, and $\leq 37$ would all be reasonable depending on the purposes of screening, and could reach a sensitivity of $87 \%$ while still being $62 \%$ specific if the $\leq 37$ cutoff was used. One advantage of the METER over the REALM-R lies in its ability to be selfadministered.

Our results showed an association of most of the independent variables (age, gender, race, preferred spoken language, educational achievement, health status, and emergency department visits) with health literacy, although the cross-sectional nature of the data does not allow us to conjecture causality. No association was detected for number of daily medications or primacy care access. This substantiates past research which has found similar associations in bivariate analyses between these variables and performance on health literacy screening tools. $^{24,25}$

Our study has some limitations. Firstly, all our patients were recruited from a single Southeastern suburban ED, and our results may not be generalizable to other EDs. Secondly, we did not perform any formal visual testing, relying on a screening question regarding use of corrective eyewear. Performance may have been decreased due to poor eyesight, or patients excluded on the grounds of needing corrective eyewear may have been able to take part, and may have been using eyesight as an excuse to avoid participating. Additionally, no cognitive screening was performed. Health literacy has been associated with cognitive abilities ${ }^{32}$ and dementia or other cognitive decline may confound our ability to measure health literacy skills. The number of consecutive tools the subjects had to complete may have led to questionnaire 
fatigue by the end of the survey, which may have decreased their predictive ability by having patients rush through the later parts instead of providing thought out responses. Finally, there is some overlap between the tools used, most notably in the words used in the REALM-R and the METER, and patients may have benefitted from seeing words used in the REALM-R and applied that knowledge to the METER. The mean of 35.5 in our sample on the METER, however, compares well with the mean of 36.1 found in the validating study. ${ }^{17}$

This is the first study to date to compare all of these screening tools in a single population, and many of these tools had not been previously validated in an ED setting. Our results indicate that the NVS was best able to identify limited health literacy on the S-TOFHLA, but that all tools performed adequately at this task and could be considered as a substitute. Our data supports the widespread differences that exist between different instruments both in their administration characteristics, the proportion of subjects it identifies as having limited health literacy, and in the nature of the underlying constructs they measure.

These different underlying constructs are important not just for the sake of consistency between health literacy studies, but because of their implications on health outcomes research. Few studies use multiple health literacy measurement tools in this type of research, and those that do have found differences in the presence and magnitude of associations with various health conditions and health-seeking behaviors. ${ }^{23,24,33}$ For clinical use, this study has shown that many brief tools can be substituted for the S-TOFHLA in health literacy screening in an ED. Future research will need to determine their specific strengths and weaknesses in predicting clinical outcomes. In the mean time, researchers and clinicians alike should think carefully about which tool to use based on the specific skills being targeted, intent of screening, and resource availability. 


\section{REFERENCES}

1. Nielsen-Bohlman L, Panzer AM. Health literacy: A prescription to end confusion. National Academy Press; 2004.

2. Kutner M, Greenburg E, Jin Y, Paulsen C. The health literacy of america's adults: Results from the 2003 national assessment of adult literacy. NCES 2006-483. National Center for Education Statistics. 2006.

3. Berkman ND, Sheridan SL, Donahue KE, Halpern DJ, Crotty K. Low health literacy and health outcomes: An updated systematic review. Ann Intern Med. 2011;155(2):97.

4. Ginde AA, Weiner SG, Pallin DJ, Camargo Jr CA. Multicenter study of limited health literacy in emergency department patients. Acad Emerg Med. 2008;15(6):577-80.

5. Herndon JB, Chaney M, Carden D. Health literacy and emergency department outcomes: A systematic review. Ann Emerg Med. 2011;57(4):334-45.

6. Kelly PA, Haidet P. Physician overestimation of patient literacy: A potential source of health care disparities. Patient Educ Couns. 2007;66(1):119.

7. Parker RM, Baker DW, Williams MV, Nurss JR. The test of functional health literacy in adults: A new instrument for measuring patients' literacy skills. J Gen Intern Med. 1995 Oct;10(10):537-41.

8. Baker DW, Williams MV, Parker RM, Gazmararian JA, Nurss J. Development of a brief test to measure functional health literacy. Patient Educ Couns. 1999.

9. Davis TC, Long SW, Jackson RH, Mayeaux E, George RB, Murphy PW, et al. Rapid estimate of adult literacy in medicine: A shortened screening instrument. Fam Med. 1993;25(6):391.

10. Paasche-Orlow MK, Parker RM, Gazmararian JA, Nielsen-Bohlman LT, Rudd RR. The prevalence of limited health literacy. Journal of General Internal Medicine. 2005;20(2):175-84.

11. Barber M, Buchbinder R, Osborne R, Elder C, Clerehan R, Busija L. Pronunciation of words is not a good measure of health literacy: Determination of the validity of the rapid estimate of adult literacy in medicine (REALM). Australian rheumatology association and the rheumatology health professional association 48th annual scientific meeting; Australia Rheumatology Association; 2012.

12. DeWalt DA, Broucksou KA, Hawk V, Brach C, Hink A, Rudd R, et al. Developing and testing the health literacy universal precautions toolkit. Nurs Outlook. 2011;59(2):85-94.

13. Green JA, Mor MK, Shields AM, Sevick MA, Arnold RM, Palevsky PM, et al. Associations of health literacy with dialysis adherence and health resource utilization in patients receiving maintenance hemodialysis. American Journal of Kidney Diseases. 2013.

14. Sharp LK, Ureste PJ, Torres LA, Bailey L, Gordon HS, Gerber BS. Time to sign: The relationship between health literacy and signature time. Patient Educ Couns. 2012.

15. Weiss BD, Mays MZ, Martz W, Castro KM, DeWalt DA, Pignone MP, et al. Quick assessment of literacy in primary care: The newest vital sign. The Annals of Family Medicine. 2005;3(6):514-22.

16. Chew LD, Bradley KA, Boyko EJ. Brief questions to identify patients with inadequate health literacy. health. 2004;11:12.

17. Rawson KA, Gunstad J, Hughes J, Spitznagel MB, Potter V, Waechter D, et al. The METER: A brief, self-administered measure of health literacy. Journal of general internal medicine. 2010;25(1):67-71.

18. Morris NS, MacLean CD, Chew LD, Littenberg B. The single item literacy screener: Evaluation of a brief instrument to identify limited reading ability. BMC Family Practice. 2006;7(1):21.

19. Bass PF, Wilson JF, Griffith CH. A shortened instrument for literacy screening. Journal of general internal medicine. 2003;18(12):1036-8.

20. McNaughton C, Wallston KA, Rothman RL, Marcovitz DE, Storrow AB. Short, subjective measures of numeracy and general health literacy in an adult emergency department. Acad Emerg Med. 2011

Nov;18(11):1148-55. 
21. Chew LD, Griffin JM, Partin MR, Noorbaloochi S, Grill JP, Snyder A, et al. Validation of screening questions for limited health literacy in a large VA outpatient population. Journal of General Internal Medicine. 2008;23(5):561-6.

22. McNaughton C, Wallston KA, Rothman RL, Marcovitz DE, Storrow AB. Short, subjective measures of numeracy and general health literacy in an adult emergency department. Acad Emerg Med. 2011

Nov;18(11):1148-55.

23. Hirsh JM, Boyle DJ, Collier DH, Oxenfeld AJ, Nash A, Quinzanos I, et al. Limited health literacy is a common finding in a public health hospital's rheumatology clinic and is predictive of disease severity. $\mathrm{J}$ Clin Rheumatol. 2011 Aug;17(5):236-41.

24. Haun J, Luther S, Dodd V, Donaldson P. Measurement variation across health literacy assessments: Implications for assessment selection in research and practice. J Health Commun. 2012;17 Suppl 3:14159.

25. Kirk JK, Grzywacz JG, Arcury TA, Ip EH, Nguyen HT, Bell RA, et al. Performance of health literacy tests among older adults with diabetes. J Gen Intern Med. 2012 May;27(5):534-40.

26. Jordan JE, Osborne RH, Buchbinder R. Critical appraisal of health literacy indices revealed variable underlying constructs, narrow content and psychometric weaknesses. J Clin Epidemiol. 2011;64(4):36679.

27. Al Sayah F, Williams B, Johnson JA. Measuring health literacy in individuals with diabetes A systematic review and evaluation of available measures. Health Education \& Behavior. 2013;40(1):42-55. 28. Osborn CY, Paasche-Orlow MK, Bailey SC, Wolf MS. The mechanisms linking health literacy to behavior and health status. Am J Health Behav. 2011 Jan-Feb;35(1):118-28.

29. Golbeck A, Paschal A, Jones A, Hsiao T. Correlating reading comprehension and health numeracy among adults with low literacy. Patient Educ Couns. 2011;84(1):132-4.

30. Patel PJ, Joel S, Rovena G, Pedireddy S, Saad S, Rachmale R, et al. Testing the utility of the newest vital sign (NVS) health literacy assessment tool in older african-american patients. Patient Educ Couns. 2011;85(3):505-7.

31. Sarkar U, Schillinger D, Lopez A, Sudore R. Validation of self-reported health literacy questions among diverse english and spanish-speaking populations. J Gen Intern Med. 2011 Mar;26(3):265-71. 32. Curtis LM, Waite KR. Literacy, cognitive function, and health: Results of the LitCog study. Journal of general internal medicine. 2012;27(10):1300-7.

33. Ciampa PJ, Osborn CY, Peterson NB, Rothman RL. Patient numeracy, perceptions of provider communication, and colorectal cancer screening utilization. J Health Commun. 2010;15(S3):157-68. 


\section{TABLES AND FIGURES}

Table 1: Characteristics of Patients Completing Tests Compared to Non-Completers

\begin{tabular}{|c|c|c|c|c|}
\hline Characteristic & $\begin{array}{l}\text { Full Sample } \\
\qquad(n=700)\end{array}$ & $\begin{array}{c}\text { Enrolled } \\
(n=400)\end{array}$ & $\begin{array}{l}\text { Refused } \\
\text { or Excluded } \\
(\mathbf{n}=\mathbf{3 0 0})\end{array}$ & $\begin{array}{c}\text { p- } \\
\text { Value }\end{array}$ \\
\hline Age, mean (SD), y & $39.9(14.7)$ & $38.4(13.8)$ & $42.0(15.7)$ & $<0.01$ \\
\hline $\begin{array}{l}\text { Sex, No. (\%) } \\
\text { Male } \\
\text { Female }\end{array}$ & $\begin{array}{l}299(43) \\
401(57)\end{array}$ & $\begin{array}{l}170(43) \\
230(58)\end{array}$ & $\begin{array}{l}129(43) \\
171(57)\end{array}$ & 0.90 \\
\hline $\begin{array}{l}\text { Race, No. }(\%) \\
\text { White/Caucasian } \\
\text { African American/Black } \\
\text { Hispanic/Latino } \\
\text { Other }\end{array}$ & $\begin{array}{r}385(55) \\
238(34) \\
64(9) \\
13(2) \\
\end{array}$ & $\begin{array}{r}252(63) \\
120(30) \\
18(5) \\
10(3) \\
\end{array}$ & $\begin{array}{r}133(44) \\
118(39) \\
46(15) \\
3(1) \\
\end{array}$ & $<0.01$ \\
\hline $\begin{array}{l}\text { Preferred Spoken Language, No. (\%) } \\
\text { English } \\
\text { Spanish } \\
\text { Other }\end{array}$ & $\begin{array}{r}640(91) \\
52(7) \\
8(1) \\
\end{array}$ & $\begin{array}{r}385(96) \\
11(3) \\
4(1) \\
\end{array}$ & $\begin{array}{r}255(85) \\
41(14) \\
4(1) \\
\end{array}$ & $<0.01$ \\
\hline $\begin{array}{l}\text { Education, No. }(\%) \\
\text { Did not complete high school } \\
\text { High school diploma or GED } \\
\text { Some education after high school } \\
\text { College degree } \\
\text { Some graduate school, or graduate degree } \\
\text { Declined to provide }\end{array}$ & $\begin{array}{r}136(19) \\
238(34) \\
209(30) \\
76(11) \\
39(6) \\
2(<1)\end{array}$ & $\begin{array}{r}62(16) \\
138(35) \\
124(31) \\
49(12) \\
27(7) \\
0(0)\end{array}$ & $\begin{array}{r}74(25) \\
100(33) \\
85(28) \\
27(9) \\
12(4) \\
2(1)\end{array}$ & 0.01 \\
\hline
\end{tabular}


Table 2: Performance on Health Literacy Tools

\begin{tabular}{|c|c|c|c|}
\hline Measurement Tool & $n(\%)$ & $\begin{array}{c}\text { Median } \\
\text { (IQR) }\end{array}$ & $\begin{array}{c}\text { Spearman's Rank Correlation } \\
\text { Coefficients } \dagger\end{array}$ \\
\hline $\begin{array}{l}\text { S-TOFHLA } \\
\text { Inadequate }(0-16) \\
\text { Marginal }(17-22) \\
\text { Adequate }(23-36) \\
\end{array}$ & $\begin{array}{r}13(3) \\
17(4) \\
370(93)\end{array}$ & $\begin{array}{c}35 \\
(32-35)\end{array}$ & $\mathrm{n} / \mathrm{a}$ \\
\hline $\begin{array}{l}\text { Newest Vital Sign } \\
\text { Limited/Possibly Limited (0-3) } \\
\text { Adequate (4-6) }\end{array}$ & $\begin{array}{r}192(48) \\
208(52) \\
\end{array}$ & $\begin{array}{c}4 \\
(2-5)\end{array}$ & $\mathrm{r}=0.62$ \\
\hline $\begin{array}{l}\text { Single Item Literacy Screen } \\
\text { Sometimes[3]/Often[4]/Always[5] have someone help } \\
\text { Never[1]/Rarely[2] have someone help }\end{array}$ & $\begin{array}{l}100(25) \\
300(75)\end{array}$ & $\begin{array}{c}1 \\
(1-2.5)\end{array}$ & $\mathrm{r}=-0.41$ \\
\hline $\begin{array}{l}\text { Problems Question } \\
\text { Sometimes[3]/Often[4]/Always[5] have problems } \\
\text { Never[1]/Occasionally[2] have problems }\end{array}$ & $\begin{array}{r}93(23) \\
307(77) \\
\end{array}$ & $\begin{array}{c}1 \\
(1-2)\end{array}$ & $\mathrm{r}=-0.40$ \\
\hline $\begin{array}{l}\text { Confidence Question } \\
\text { Never[1]/Occasionally[2]/Sometimes[3] confident } \\
\text { Often[4]/Always[5] confident }\end{array}$ & $\begin{array}{r}99(25) \\
301(75) \\
\end{array}$ & $\begin{array}{c}5 \\
(4-5)\end{array}$ & $\mathrm{r}=0.39$ \\
\hline $\begin{array}{l}\text { Help } \text { Question } \\
\text { Sometimes[3]/Often[4]/Always[5] need help } \\
\text { Never[1]/Occasionally[2] need help }\end{array}$ & $\begin{array}{r}78(20) \\
322(81)\end{array}$ & $\begin{array}{c}1 \\
(1-2)\end{array}$ & $\mathrm{r}=-0.42$ \\
\hline $\begin{array}{l}\text { REALM-R } \\
\text { At risk (0-6 words correct) } \\
\text { Not in at risk category ( } 7-8 \text { words correct) }\end{array}$ & $\begin{array}{l}144(36) \\
256(64)\end{array}$ & $\begin{array}{c}7 \\
(5.5-8)\end{array}$ & $\mathrm{r}=0.56$ \\
\hline $\begin{array}{l}\text { METER } \\
\text { Low/Marginal }(0-34) \\
\text { Functional }(35-40)\end{array}$ & $\begin{array}{r}84(21) \\
316(79)\end{array}$ & $\begin{array}{c}38 \\
(36-39)\end{array}$ & $\mathrm{r}=0.53$ \\
\hline
\end{tabular}

t : All correlation coefficients compared to S-TOFHLA. All coefficients statistically significant, $\mathrm{p}<0.001$ 
Table 3: Ability of Health Literacy Tools to Detect Low/Marginal Health Literacy $(n=400)^{\dagger}$

\begin{tabular}{|c|c|c|c|c|c|}
\hline $\begin{array}{l}\text { Screening Tool } \\
\text { Cutoff Point }\end{array}$ & $\begin{array}{l}\text { AUROC } \\
(95 \% \text { CI })\end{array}$ & Sensitivity & Specificity & LR+ & LR- \\
\hline $\begin{array}{l}\text { Newest Vital Sign } \\
\leq 6 \\
\leq 5 \\
\leq 4 \\
\leq 3 \\
\leq 2 \\
\leq 1 \\
\leq 0\end{array}$ & $\begin{array}{c}0.89 \\
(0.85-0.94)\end{array}$ & $\begin{array}{l}1.00 \\
1.00 \\
1.00 \\
\mathbf{0 . 9 7} \\
0.93 \\
0.87 \\
0.37 \\
\end{array}$ & $\begin{array}{l}0.00 \\
0.23 \\
0.41 \\
\mathbf{0 . 5 6} \\
0.69 \\
0.86 \\
0.94 \\
\end{array}$ & $\begin{array}{l}1.00 \\
1.30 \\
1.68 \\
2.19 \\
3.03 \\
6.12 \\
5.90\end{array}$ & $\begin{array}{l}---- \\
0.00 \\
0.00 \\
\mathbf{0 . 0 6} \\
0.10 \\
0.16 \\
0.68\end{array}$ \\
\hline $\begin{array}{l}\text { Single Item Literacy Screen } \\
\geq \text { Never } \\
\geq \text { Rarely } \\
\geq \text { Sometimes } \\
\geq \text { Often } \\
\geq \text { Always }\end{array}$ & $\begin{array}{c}0.78 \\
(0.70-0.87)\end{array}$ & $\begin{array}{l}1.00 \\
0.83 \\
\mathbf{0 . 7 3} \\
0.27 \\
0.20 \\
\end{array}$ & $\begin{array}{l}0.00 \\
0.58 \\
\mathbf{0 . 7 9} \\
0.99 \\
1.00 \\
\end{array}$ & $\begin{array}{r}1.00 \\
1.98 \\
\mathbf{3 . 4 8} \\
4.70 \\
14.80 \\
\end{array}$ & $\begin{array}{l}----- \\
0.29 \\
\mathbf{0 . 3 4} \\
0.78 \\
0.81 \\
\end{array}$ \\
\hline $\begin{array}{l}\text { Problems Question } \\
\geq \text { Never } \\
\geq \text { Occasionally } \\
\geq \text { Sometimes } \\
\geq \text { Often } \\
\geq \text { Always }\end{array}$ & $\begin{array}{c}0.75 \\
(0.65-0.85)\end{array}$ & $\begin{array}{l}1.00 \\
0.77 \\
\mathbf{0 . 6 7} \\
0.27 \\
0.13\end{array}$ & $\begin{array}{l}0.00 \\
0.58 \\
\mathbf{0 . 8 0} \\
0.94 \\
0.99\end{array}$ & $\begin{array}{r}1.00 \\
1.83 \\
\mathbf{3 . 3 8} \\
4.48 \\
12.33\end{array}$ & $\begin{array}{l}---- \\
0.40 \\
\mathbf{0 . 4 2} \\
0.78 \\
0.88\end{array}$ \\
\hline $\begin{array}{l}\text { Confidence Question } \\
\leq \text { Always } \\
\leq \text { Often } \\
\leq \text { Sometimes } \\
\leq \text { Occasionally } \\
\leq \text { Never }\end{array}$ & $\begin{array}{c}0.76 \\
(0.67-0.85)\end{array}$ & $\begin{array}{l}1.00 \\
0.80 \\
\mathbf{0 . 6 7} \\
0.37 \\
0.27 \\
\end{array}$ & $\begin{array}{l}0.00 \\
0.62 \\
\mathbf{0 . 7 9} \\
0.90 \\
0.96 \\
\end{array}$ & $\begin{array}{l}1.00 \\
2.11 \\
\mathbf{3 . 1 2} \\
3.57 \\
6.58 \\
\end{array}$ & $\begin{array}{l}----- \\
0.32 \\
\mathbf{0 . 4 2} \\
0.71 \\
0.76 \\
\end{array}$ \\
\hline $\begin{array}{l}\text { Help Question } \\
\geq \text { Never } \\
\geq \text { Occasionally } \\
\geq \text { Sometimes } \\
\geq \text { Often } \\
\geq \text { Always }\end{array}$ & $\begin{array}{c}0.80 \\
(0.71-0.89)\end{array}$ & $\begin{array}{l}1.00 \\
0.80 \\
\mathbf{0 . 6 3} \\
0.43 \\
0.33 \\
\end{array}$ & $\begin{array}{l}0.00 \\
0.71 \\
\mathbf{0 . 8 4} \\
0.94 \\
0.97 \\
\end{array}$ & $\begin{array}{r}1.00 \\
2.77 \\
\mathbf{3 . 9 7} \\
6.68 \\
12.33 \\
\end{array}$ & $\begin{array}{l}----- \\
0.28 \\
\mathbf{0 . 4 4} \\
0.61 \\
0.69 \\
\end{array}$ \\
\hline $\begin{array}{l}\text { Short Literacy Survey } \\
\leq 15 \\
\leq 14 \\
\leq 13 \\
\leq 12 \\
\leq 11 \\
\leq 10 \\
\leq 9 \\
\leq 8\end{array}$ & $\begin{array}{c}0.82 \\
(0.73-0.91)\end{array}$ & $\begin{array}{l}1.00 \\
0.90 \\
0.83 \\
0.83 \\
0.80 \\
0.73 \\
0.63 \\
0.43\end{array}$ & $\begin{array}{l}0.00 \\
0.42 \\
0.58 \\
0.69 \\
0.77 \\
0.84 \\
0.90 \\
0.92\end{array}$ & $\begin{array}{l}1.00 \\
1.55 \\
1.96 \\
2.66 \\
3.48 \\
4.76 \\
6.17 \\
5.53 \\
\end{array}$ & $\begin{array}{l}---- \\
0.24 \\
0.29 \\
0.24 \\
0.26 \\
0.32 \\
0.41 \\
0.61\end{array}$ \\
\hline
\end{tabular}




\begin{tabular}{|c|c|c|c|c|c|}
\hline$\leq 7$ & & 0.30 & 0.95 & 6.17 & 0.74 \\
\hline$\leq 6$ & & 0.27 & 0.99 & 19.73 & 0.74 \\
\hline$\leq 5$ & & 0.23 & 0.99 & 21.58 & 0.78 \\
\hline$\leq 4$ & & 0.10 & 0.99 & 18.50 & 0.90 \\
\hline$\leq 3$ & & 0.07 & 1.00 & ----- & 0.93 \\
\hline REALM-R & & & & & \\
\hline$\leq 8$ & & 1.00 & 0.00 & 1.00 & ----- \\
\hline$\leq 7$ & & 0.93 & 0.47 & 1.75 & 0.14 \\
\hline$\leq 6$ & & 0.83 & 0.68 & 2.59 & 0.25 \\
\hline$\leq 5$ & 0.84 & 0.80 & 0.79 & 3.89 & 0.25 \\
\hline$\leq 4$ & $(0.77-0.92)$ & 0.67 & 0.84 & 4.25 & 0.40 \\
\hline$\leq 3$ & & 0.60 & 0.88 & 5.16 & 0.45 \\
\hline$\leq 2$ & & 0.57 & 0.92 & 6.76 & 0.47 \\
\hline$\leq 1$ & & 0.50 & 0.95 & 9.74 & 0.53 \\
\hline$\leq 0$ & & 0.23 & 0.97 & 7.85 & 0.79 \\
\hline METER & & & & & \\
\hline$\leq 40$ & & 1.00 & 0.00 & 1.00 & ----- \\
\hline$\leq 39$ & & 0.90 & 0.10 & 1.00 & 0.97 \\
\hline$\leq 38$ & & 0.87 & 0.33 & 1.29 & 0.41 \\
\hline$\leq 37$ & & 0.87 & 0.62 & 2.27 & 0.22 \\
\hline$\leq 36$ & & 0.83 & 0.74 & 3.21 & 0.23 \\
\hline$\leq 35$ & & 0.80 & 0.80 & 4.05 & 0.25 \\
\hline$\leq 34$ & & 0.77 & 0.84 & 4.65 & 0.28 \\
\hline$\leq 33$ & & 0.70 & 0.85 & 4.80 & 0.35 \\
\hline$\leq 32$ & & 0.70 & 0.88 & 6.02 & 0.34 \\
\hline$\leq 31$ & & 0.67 & 0.90 & 6.49 & 0.37 \\
\hline$\leq 30$ & & 0.67 & 0.92 & 8.22 & 0.36 \\
\hline$\leq 29$ & & 0.67 & 0.93 & 9.14 & 0.36 \\
\hline$\leq 28$ & & 0.60 & 0.94 & 9.25 & 0.43 \\
\hline$\leq 27$ & & 0.57 & 0.94 & 9.53 & 0.46 \\
\hline$\leq 26$ & 0.82 & 0.57 & 0.94 & 9.98 & 0.46 \\
\hline$\leq 25$ & $(0.71-0.93)$ & 0.53 & 0.95 & 10.39 & 0.49 \\
\hline$\leq 24$ & & 0.53 & 0.95 & 11.61 & 0.49 \\
\hline$\leq 22$ & & 0.47 & 0.96 & 13.28 & 0.55 \\
\hline$\leq 21$ & & 0.40 & 0.97 & 12.33 & 0.62 \\
\hline$\leq 20$ & & 0.37 & 0.97 & 12.33 & 0.65 \\
\hline$\leq 19$ & & 0.37 & 0.98 & 16.96 & 0.65 \\
\hline$\leq 18$ & & 0.30 & 0.98 & 15.86 & 0.71 \\
\hline$\leq 17$ & & 0.30 & 0.99 & 22.20 & 0.71 \\
\hline$\leq 15$ & & 0.30 & 0.99 & 27.75 & 0.71 \\
\hline$\leq 14$ & & 0.27 & 0.99 & 32.89 & 0.74 \\
\hline$\leq 12$ & & 0.20 & 0.99 & 24.67 & 0.81 \\
\hline$\leq 11$ & & 0.13 & 0.99 & 24.67 & 0.87 \\
\hline$\leq 10$ & & 0.07 & 0.99 & 12.33 & 0.94 \\
\hline$\leq 8$ & & 0.07 & 1.00 & 24.67 & 0.94 \\
\hline$\leq 6$ & & 0.03 & 1.00 & 12.33 & 0.97 \\
\hline$\leq 0$ & & 0.03 & 1.00 & ----- & 0.97 \\
\hline
\end{tabular}

t: Recommended cutoffs shown in bold for inadequate/marginal health literacy 
Table 4: Characteristics of Patients Stratified by Health Literacy Level

\begin{tabular}{|c|c|c|c|c|}
\hline Characteristic & $\begin{array}{c}\text { Enrolled } \\
(\mathrm{n}=400)\end{array}$ & $\begin{array}{c}\text { Limited } \\
\text { Health } \\
\text { Literacyt } \\
(\mathbf{n}=\mathbf{3 0})\end{array}$ & $\begin{array}{l}\text { Adequate } \\
\text { Health } \\
\text { Literacy } \\
(\mathbf{n}=\mathbf{3 7 0}) \\
\end{array}$ & $\begin{array}{c}\text { p- } \\
\text { Value }\end{array}$ \\
\hline Age, mean (SD), y & $38.4(13.8)$ & $50.0(14.5)$ & $37.4(13.3)$ & $<0.01$ \\
\hline $\begin{array}{l}\text { Sex, No. }(\%) \\
\text { Male } \\
\text { Female }\end{array}$ & $\begin{array}{l}170(43) \\
230(58) \\
\end{array}$ & $\begin{array}{l}18(60) \\
12(40) \\
\end{array}$ & $\begin{array}{l}152(41) \\
218(59) \\
\end{array}$ & 0.04 \\
\hline $\begin{array}{l}\text { Race, No. (\%) } \\
\text { White/Caucasian } \\
\text { African American/Black } \\
\text { Hispanic/Latino } \\
\text { Other }\end{array}$ & $\begin{array}{r}252(63) \\
120(30) \\
18(5) \\
10(3) \\
\end{array}$ & $\begin{array}{r}11(37) \\
12(40) \\
4(13) \\
3(10)\end{array}$ & $\begin{array}{r}241(65) \\
108(29) \\
14(4) \\
7(2) \\
\end{array}$ & $<0.01$ \\
\hline $\begin{array}{l}\text { Preferred Spoken Language, No. (\%) } \\
\text { English } \\
\text { Spanish } \\
\text { Other }\end{array}$ & $\begin{array}{r}385(96) \\
11(3) \\
4(1) \\
\end{array}$ & $\begin{array}{r}24(80) \\
4(13) \\
2(7) \\
\end{array}$ & $\begin{array}{r}361(98) \\
7(2) \\
2(1) \\
\end{array}$ & $<0.01$ \\
\hline $\begin{array}{l}\text { Education, No. }(\%) \\
\text { Did not complete high school } \\
\text { High school diploma or GED } \\
\text { Some education after high school } \\
\text { College degree } \\
\text { Some graduate school, or graduate degree }\end{array}$ & $\begin{array}{r}62(16) \\
138(35) \\
124(31) \\
49(12) \\
27(7) \\
\end{array}$ & $\begin{array}{r}13(43) \\
14(47) \\
3(10) \\
0(0) \\
0(0)\end{array}$ & $\begin{array}{r}49(13) \\
124(34) \\
121(33) \\
49(13) \\
27(7)\end{array}$ & $<0.01$ \\
\hline $\begin{array}{l}\text { Self-Reported Health Status, No. (\%) } \\
\text { Poor/Fair } \\
\text { Good/Very Good/Excellent } \\
\text { Declined }\end{array}$ & $\begin{array}{r}133(33) \\
266(67) \\
1(<1)\end{array}$ & $\begin{array}{r}19(63) \\
11(37) \\
0(0)\end{array}$ & $\begin{array}{r}114(31) \\
255(69) \\
1(<1)\end{array}$ & $<0.01$ \\
\hline \# Daily Medications, mean (SD) & $2.5(3.6)$ & $3.6(3.2)$ & $2.4(3.6)$ & 0.08 \\
\hline \# Emergency Department Visits, last 12 mo., mean (SD) & $2.9(3.2)$ & $4.0(3.4)$ & $2.8(3.2)$ & 0.04 \\
\hline $\begin{array}{l}\text { Primacy Care, No. }(\%) \\
\text { Patient has a primary care provider } \\
\text { Patient does not have a primary care provider }\end{array}$ & $\begin{array}{l}247(62) \\
153(38) \\
\end{array}$ & $\begin{array}{l}14(47) \\
16(53) \\
\end{array}$ & $\begin{array}{l}233(63) \\
137(37) \\
\end{array}$ & 0.08 \\
\hline \# Primacy Care Visits, last 12 mo., mean (SD) & $3.7(4.5)$ & $2.23(3.17)$ & $2.31(4.01)$ & 0.91 \\
\hline
\end{tabular}

t: Combined categories of limited (scores of 0-16) and marginal (17-22) health literacy on S-TOFHLA 
Figure 1

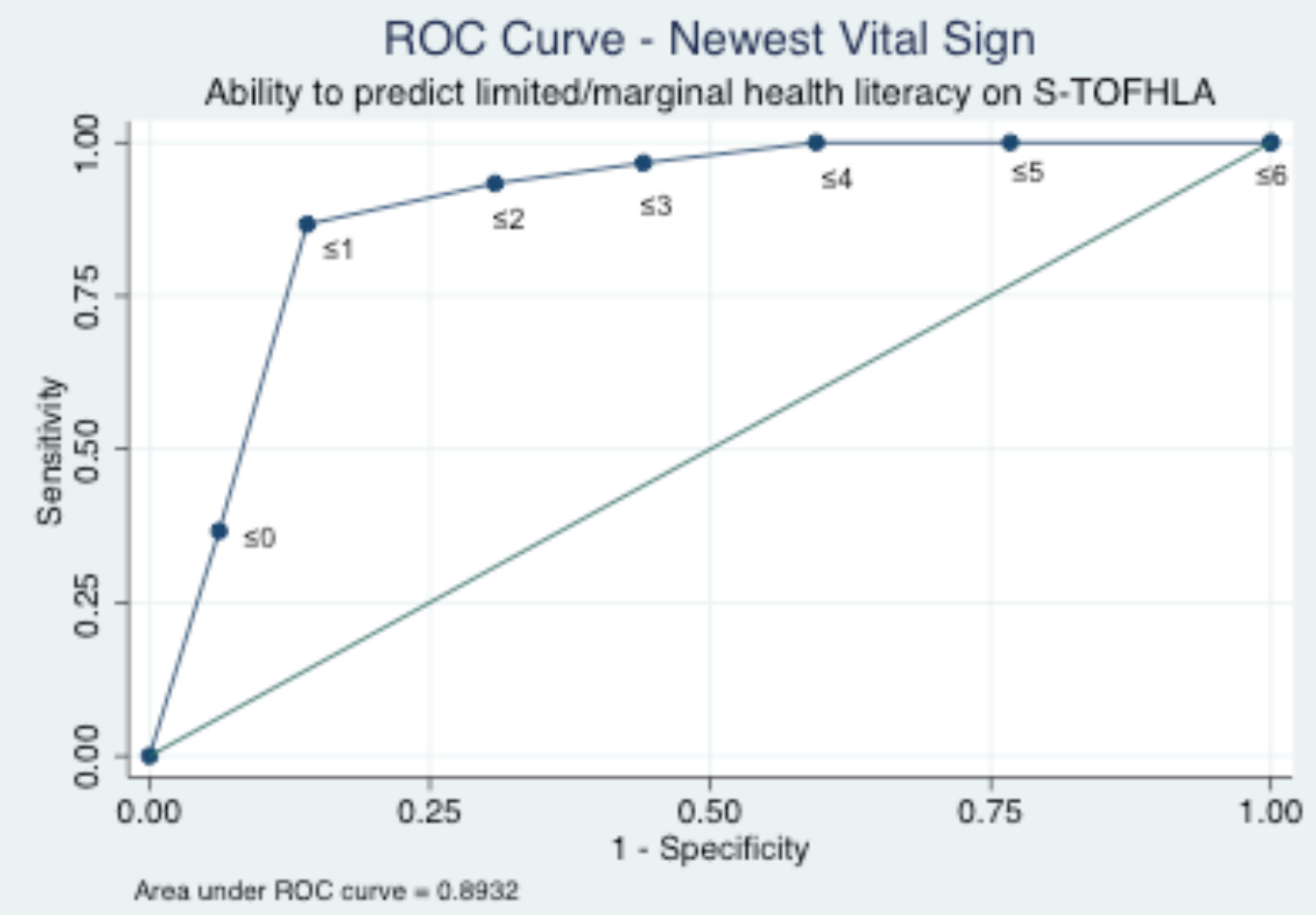

Figure 2

ROC Curve - SILS

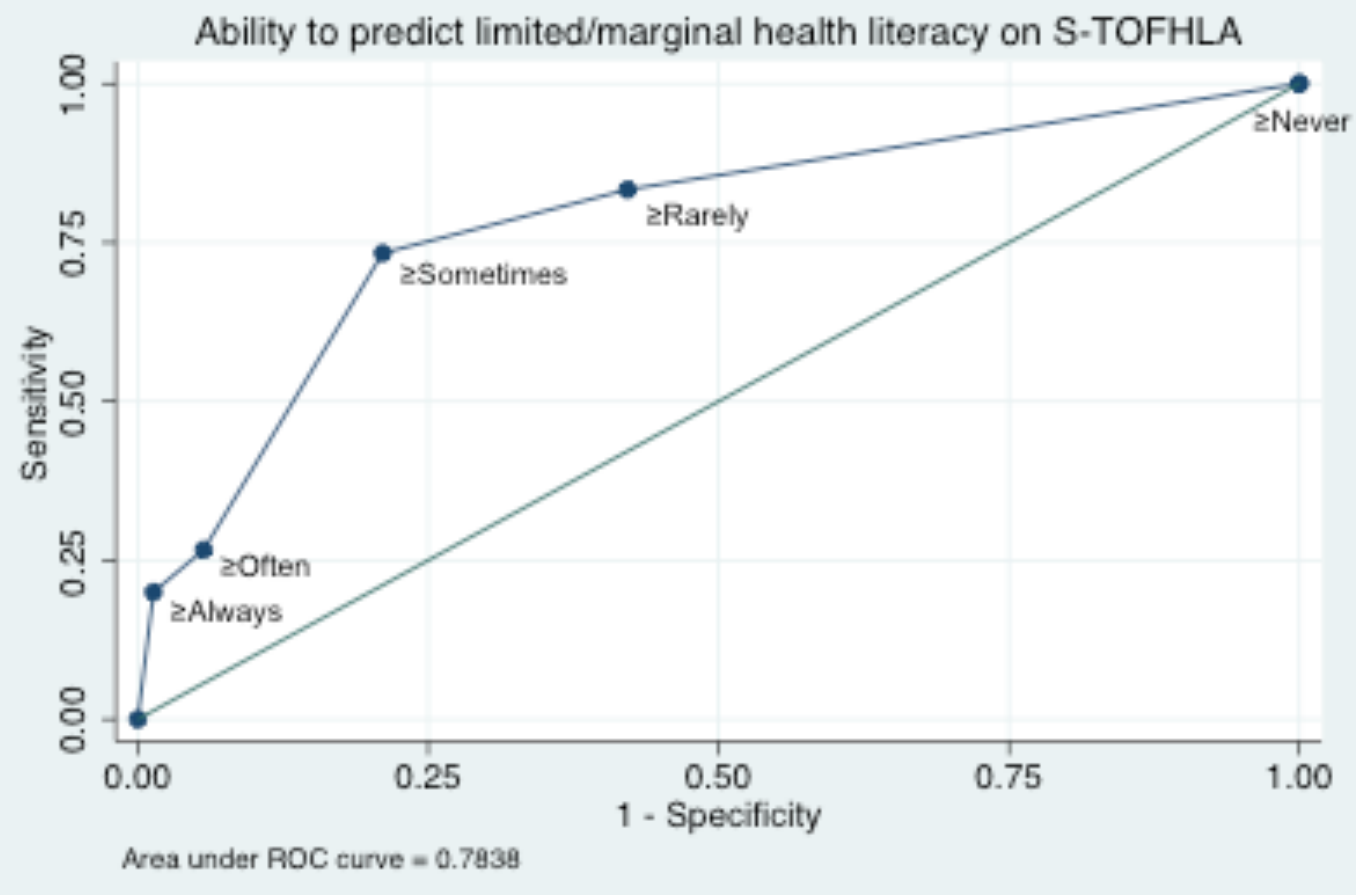




\section{Figure 3}

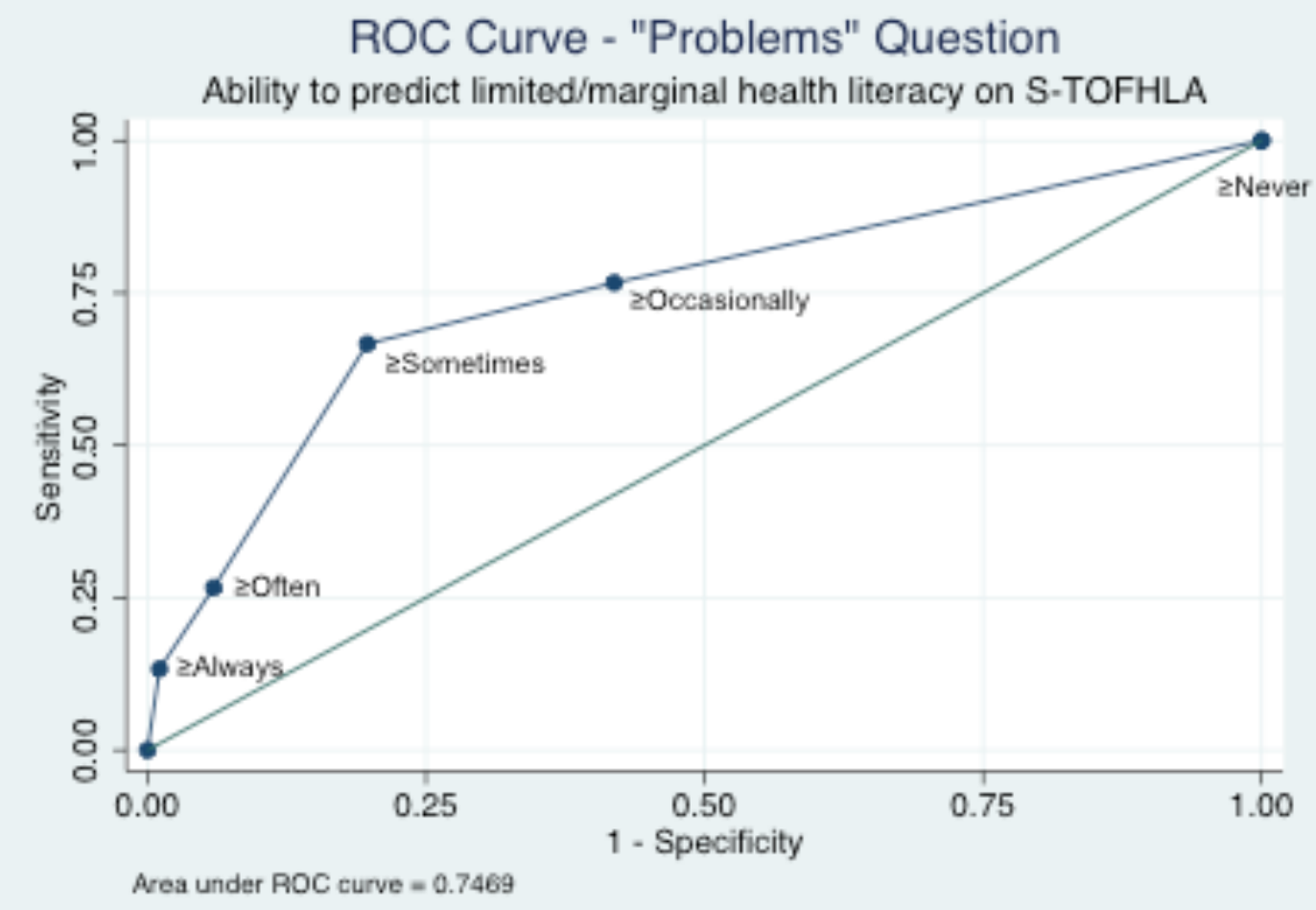

Figure 4

ROC Curve - "Confidence" Question

Ability to predict limited/marginal health literacy on S-TOFHLA

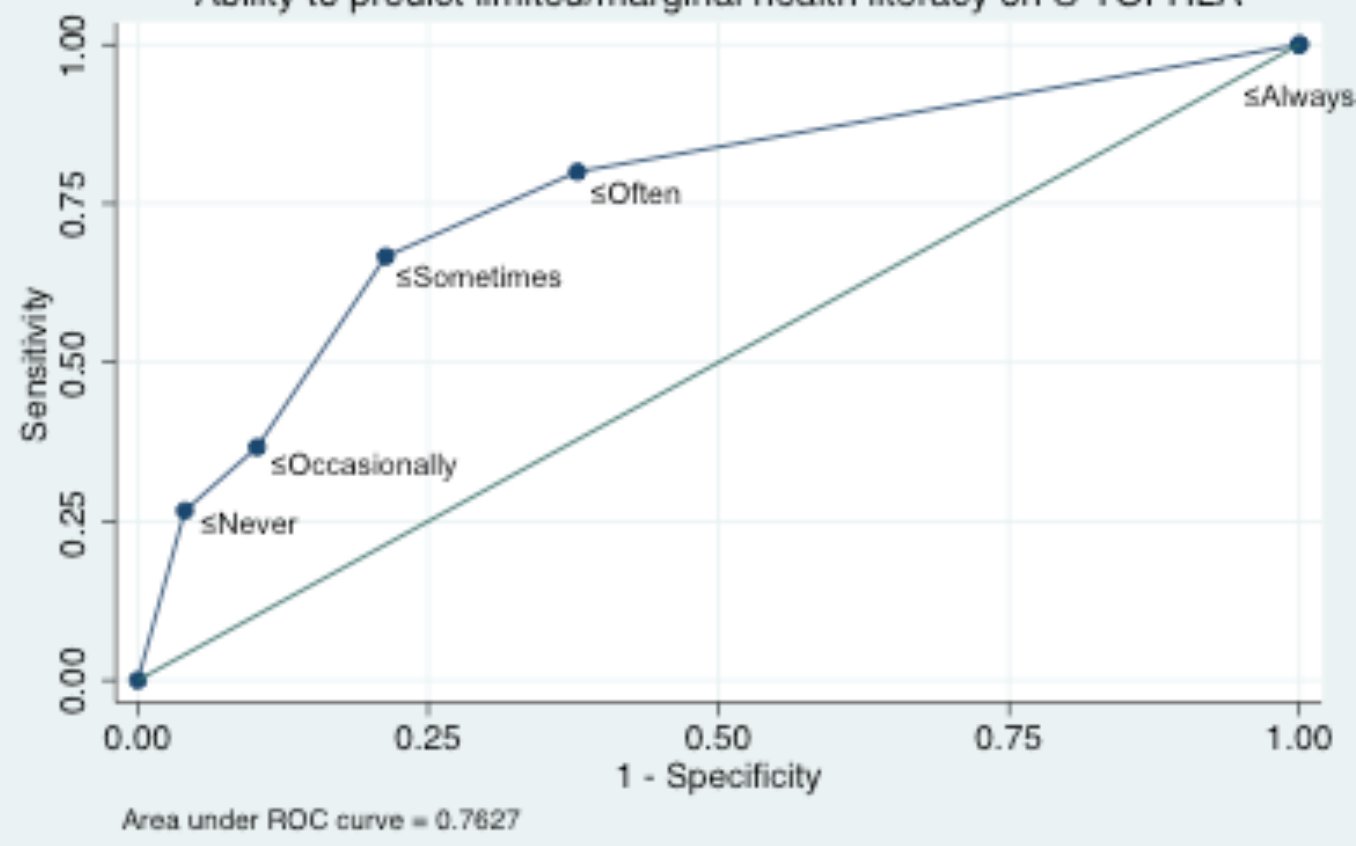




\section{Figure 5}

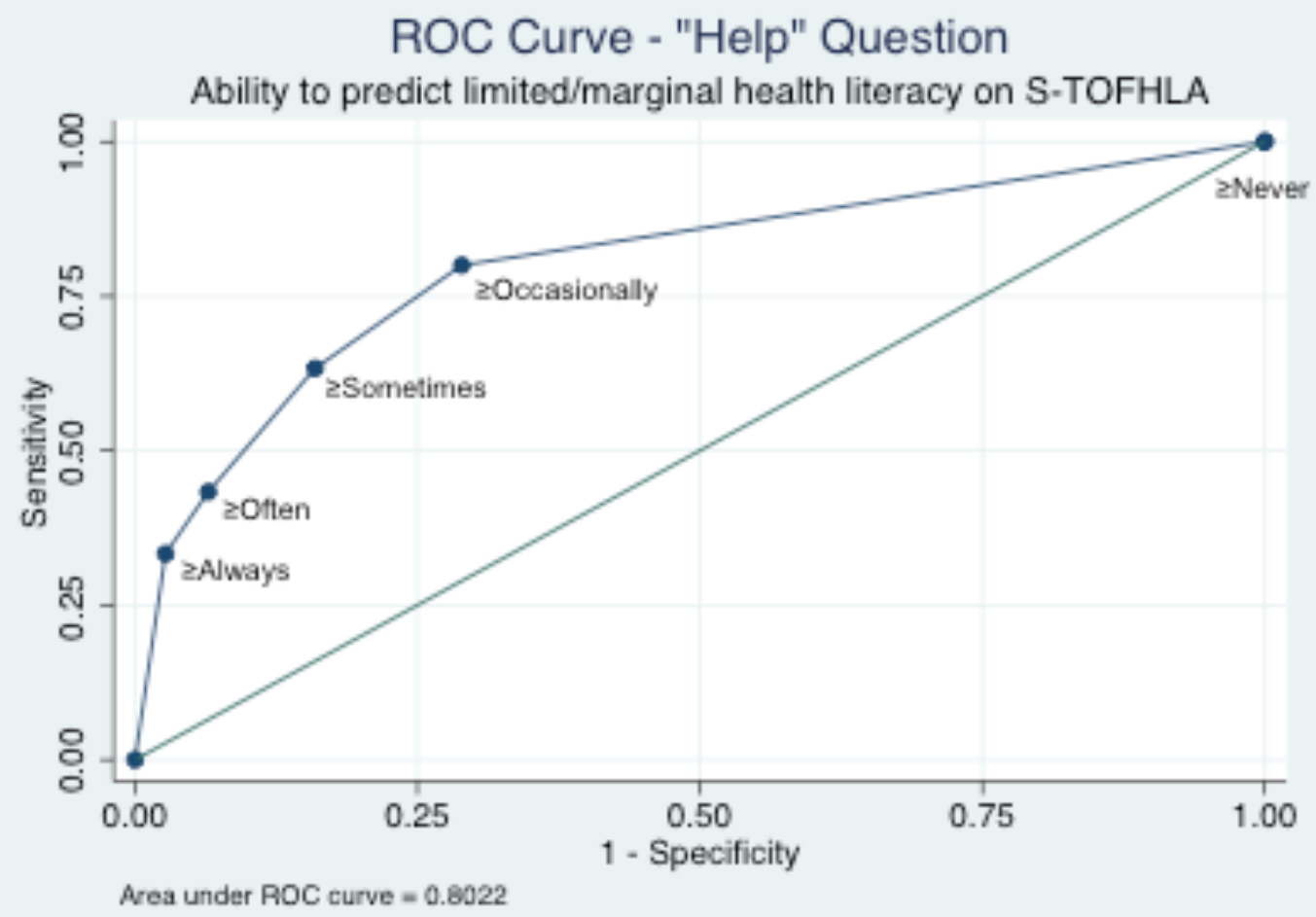

Figure 6

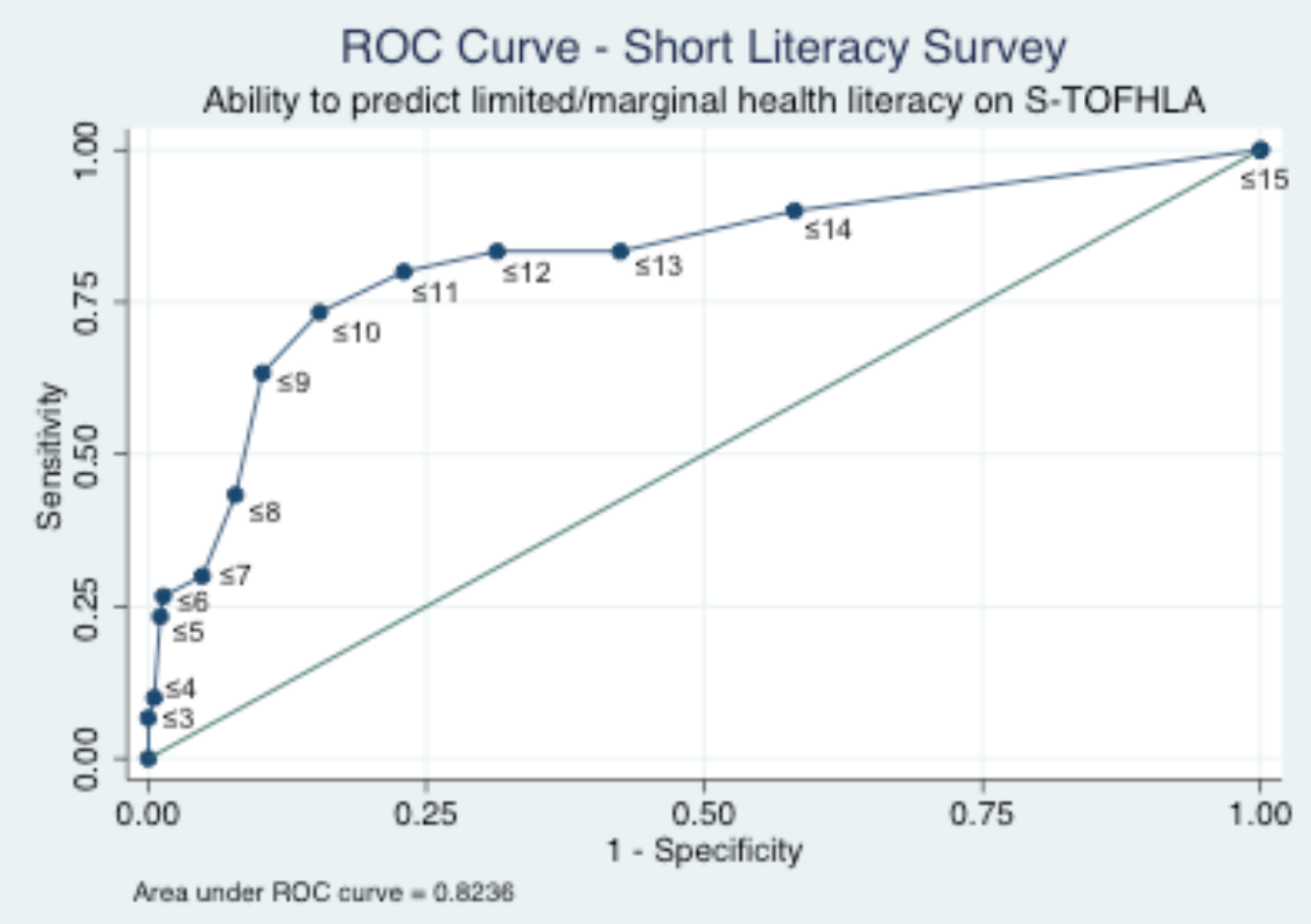




\section{Figure 7}

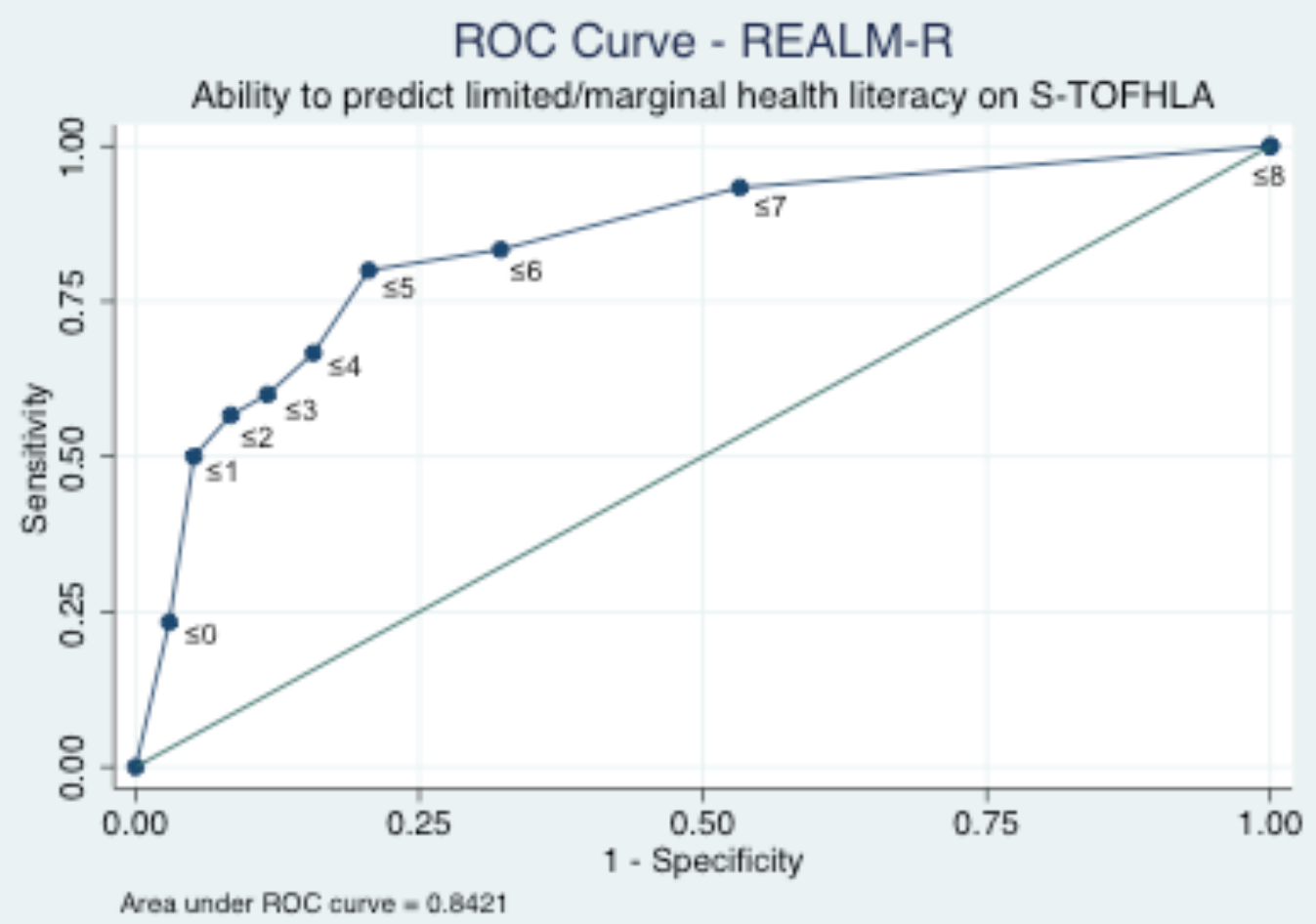

Figure 8

ROC Curve - METER

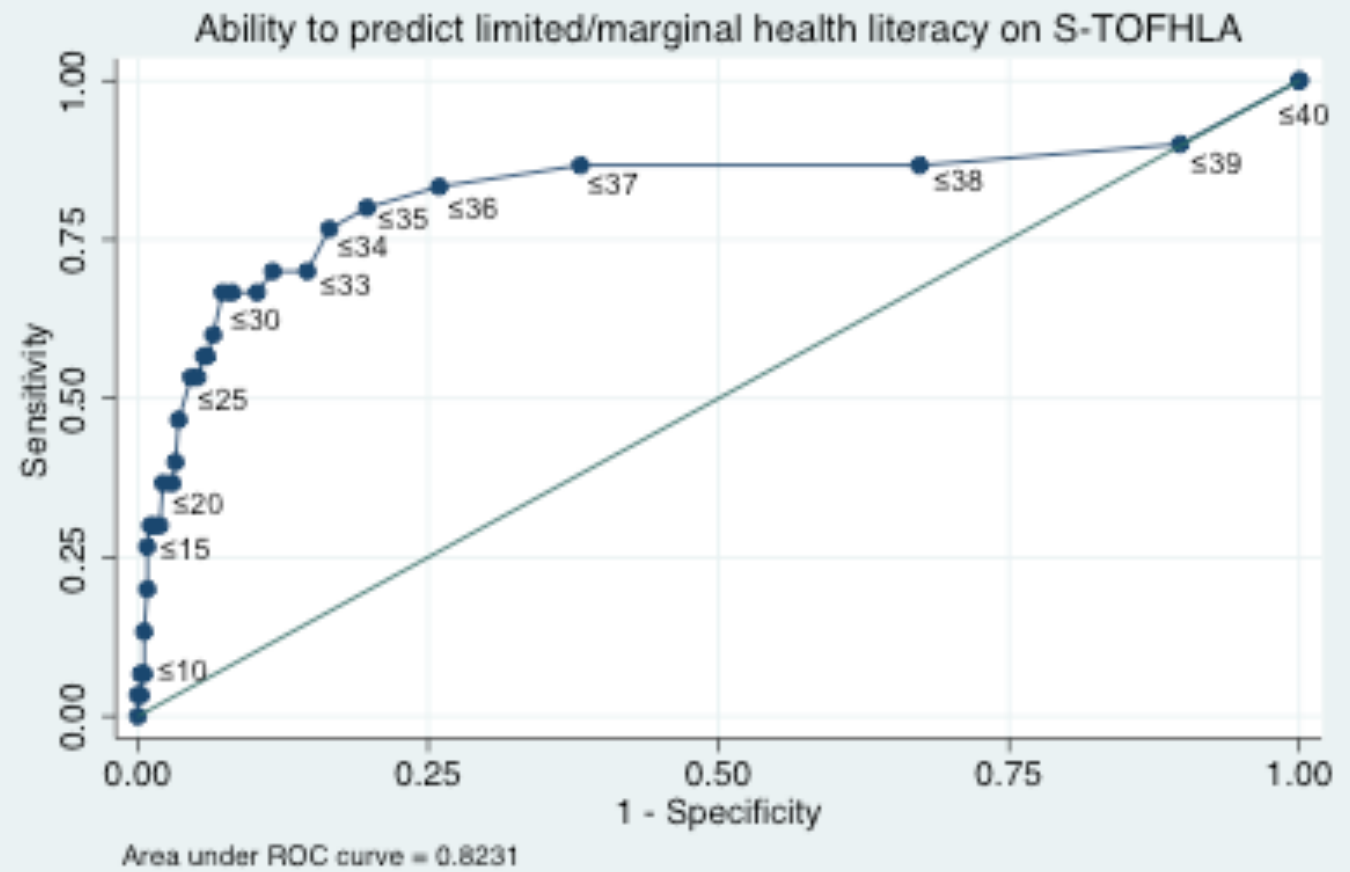

Area under ROC curve $=0.8231$ 


\section{ACKNOWLEDGEMENTS}

Through their time planning, editing, guiding, or collecting data, all of these individuals were instrumental in creating this project. This paper would not have been possible without them, and it is with gratitude that I recognize them here.

Jane Brice, MD/MPH

Associate Professor, Emergency Medicine, UNC

Orange County EMS Director

Anthony Viera, MD/MPH

Distinguished Associate Professor, Family Medicine, UNC

Adjunct Associate Professor, Public Health Leadership, Gillings School of Global Public Health

Russ Harris, MD/MPH

Professor, Medicine, UNC

Adjunct Professor, Public Health Leadership, Gillings School of Global Public Health

Stacey Sheridan, MD/MPH

Associate Professor, Medicine, UNC

Adjunct Associate Professor, Public health Leadership, Gillings School of Global Public Health

Andrew Hnat, BS

MSII, UNC School of Medicine

Ken Norman, BS

Health Unit Coordinator, UNC Health Care 